"This is the peer reviewed version of the following article: Chemistry A European Journal which has been published in final form at http://onlinelibrary.wiley.com/doi/10.1002/chem.201402509/abstract. This article may be used for noncommercial purposes in accordance with Wiley Terms and Conditions for Self-Archiving."

\title{
Metal-catalyzed Reductive Coupling Reactions of Organic Halides with Carbonyl-type Compounds
}

Toni Moragas $^{[a]}$, Arkaitz Correa ${ }^{*[a]}$ and Ruben Martin ${ }^{\star[a, b]}$

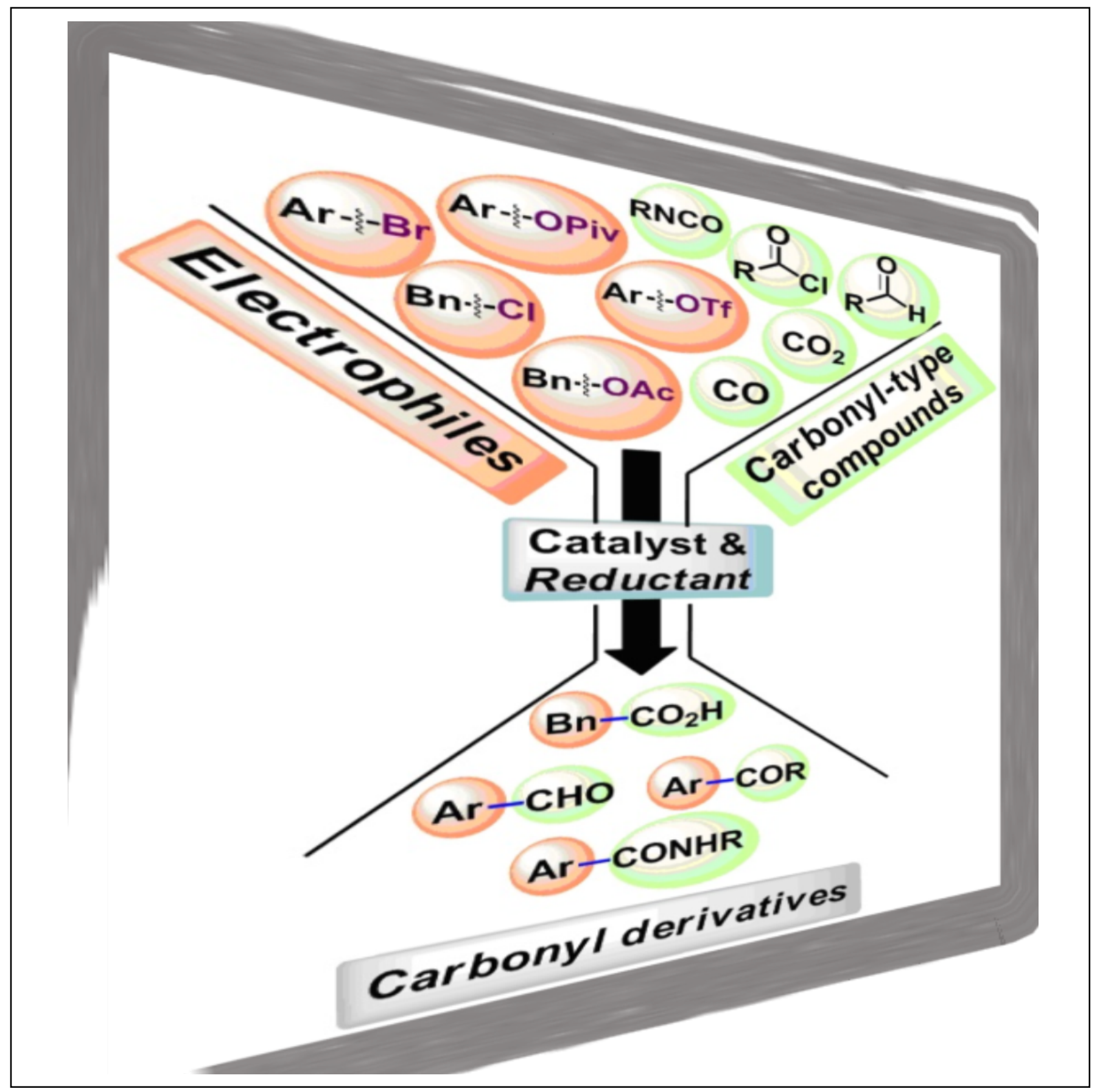




\section{Introduction}

Abstract: Metal-catalyzed reductive couplings of aryl halides and (pseudo)halides with carbonyl-type compounds have undergone impressive development along the last years. These methodologies have shown to be a powerful alternate strategy, practicality aside, to the use of stoichiometric, well- defined and, in some cases, air-sensitive organometallic species. In this review, the recent findings in this field are summarized, with particular emphasis on the mechanistic interpretation of the results and the future aspects of this area of expertise.
Metal-catalyzed cross-coupling reactions have undoubtedly changed the landscape of organic synthesis, allowing for the design of innovative, yet practical, tactics for the formation of carbon-carbon and carbon-heteroatom bonds. ${ }^{[1]}$ Importantly, these technologies have found immediate application when preparing agrochemicals, polymers and pharmaceuticals, among others. Indeed, it is rather difficult to find any advanced total synthesis of target molecules of considerable complexity that do not use a metal-catalyzed cross-coupling event. The underlying mechanisms of such "classical" transformations tacitly suggest that nucleophiles react with electrophilic counterparts assisted by a transition metal (Scheme 1, path a). Thus, a myriad of different cross-coupling methodologies have been reported under such premise. ${ }^{[1]}$ The success of these "classical" cross-coupling reactions has contributed to the perception that we have all the methods that we need to build up molecular complexity. Fortunately, scepticism, uncertainty and, in particular, curiosity has always been the main driving force behind scientific activity. Indeed, the number of possible combinations of two or more substances in the presence of a certain catalyst is virtually astronomical, indicating that crosscoupling methodologies cannot be simply limited to a simple combination of a nucleophile with an electrophilic partner. Such a vision has inspired chemists to design new techniques within the cross-coupling arena by using unconventional substrate combinations, thus increasing our ever-growing organic chemistry portfolio. Among them, the metal-catalyzed oxidative cross-coupling reaction of two different carbon nucleophiles has shown to be a powerful alternative when designing new carboncarbon bond-forming reactions (Scheme 1, path b). ${ }^{[2}$ ] Unfortunately, however, the air sensitivity and low chemoselectivity profile of Grignard reagents, organozinc or organoboron species, together with their low accessibility limit the application profile of these elegant processes.

[a] Dr. T. Moragas, Dr. A. Correa, Prof. Dr. R. Martin Institute of Chemical Research of Catalonia (ICIQ) Av. Països Catalans, 16 43007, Tarragona (Spain) Fax: (+34) 977-920-222

E-mail: rmartinromo@iciq.es; acorrea@iciq.es

[b] Prof. Dr. R. Martin

Catalan Institution for Research and Advanced Studies (ICREA) Passeig Lluïs Companys, 23

08010 Barcelona, Spain
a) $\mathrm{Nu}^{\ominus}+\mathrm{E}^{\oplus} \stackrel{\text { catalyst }}{\longrightarrow} \mathrm{Nu}-\mathrm{E}$
Traditional cross- coupling reaction
b) $\mathrm{Nu}_{1}^{\ominus}+\mathrm{Nu}_{2}^{\ominus} \underset{\text { Oxidant }}{\stackrel{\text { catalyst }}{\longrightarrow}} \mathrm{Nu}_{1}-\mathrm{Nu}_{2}$
Oxidative cross-
c) $\mathrm{E}_{1}^{\oplus}+\mathrm{E}_{2}^{\oplus} \underset{\text { Reductant }}{\stackrel{\text { catalyst }}{\text { Reduction }}} \mathrm{E}_{1}-\mathrm{E}_{2} \quad \begin{aligned} & \text { Reductive cross- } \\ & \text { coupling reaction }\end{aligned}$
d) $\mathrm{E}^{\oplus}+\underset{\mathrm{X}^{-}}{\stackrel{\mathrm{O}}{\mathrm{R}^{1}}} \stackrel{\text { catalyst }}{\text { Reductant }} \mathrm{E} \underset{\mathrm{R}^{1}}{\mathrm{O}}$ or $\mathrm{E} \underset{\mathrm{R}^{1}}{\mathrm{O}} \mathrm{X}^{\mathrm{H}}$ This review

Scheme 1. Classical cross-coupling reactions vs unconventional oxidative or reductive coupling events.

Commonly employed organometallic species in crosscoupling reactions are typically prepared from the corresponding organic halides. ${ }^{[3]}$ Therefore, the ability to promote a catalytic cross-coupling event of organic halides with an additional electrophilic partner would be highly appreciated (Scheme 1, path c). The advantages for developing such a route are primarily associated to the readily availability of organic halides and the avoidance of stoichiometric and highly reactive organometallic species. However, the inherent low reactivity of electrophiles and the proclivity towards undesired pathways constitute serious drawbacks to be overcome. The recent years have witnessed the development of new metalcatalyzed reductive coupling reactions of organic halides, achieving a high degree of molecular complexity while increasing the applicability of these synthetically attractive transformations. ${ }^{[4,5]}$ Although different electrophilic counterparts can be utilized with remarkable efficiency ${ }_{,}{ }^{[5]}$ the use of carbonyltype compounds is particularly attractive since these motifs rank amongst the most versatile synthons in organic synthesis. ${ }^{[3]}$ Therefore, the utilization of such motifs would allow the rapid and straightforward synthesis of advanced intermediates possessing the carbonyl unit, increasing the flexibility in synthetic design (Scheme 1 , path $\mathrm{d}$ ). ${ }^{[6]}$ While realizing the preparative potential of such reductive coupling events, we identified a need to review the most recent advances in this vibrant field of expertise when utilizing organic halides and carbonyl-type compounds, including the use of $\mathrm{CO}$ or even $\mathrm{CO}_{2}$ as coupling partners. The latter is particularly interesting as the use of $\mathrm{CO}_{2}$ in reductive cleavage events could potentially revolutionize the means to access carboxylic acids in a direct fashion from simple renewable carbon feedstock. Although formidable advances have been reported within the field of electrochemistry, ${ }^{[7]}$ the purpose of this review is to primarily focus on the most recent and important developments in metalcatalyzed reductive coupling reactions with carbonyl-type compounds over the last years not promoted by 
electrochemical methods, including synthetic applications and mechanistic aspects, when applicable.

Toni Moragas Solà was born in 1984 in Barcelona (Spain). He conducted his undergraduate studies at the University of Barcelona, obtaining his M.Sc. in 2009. He then moved to the United Kingdom to carry out his PhD studies under the guidance of Dr. Robert Stockman at the University of Nottingham. In 2013, he moved to his current position as a postdoctoral fellow in the laboratories of Prof. Ruben Martin at ICIQ (Tarragona). His research interests

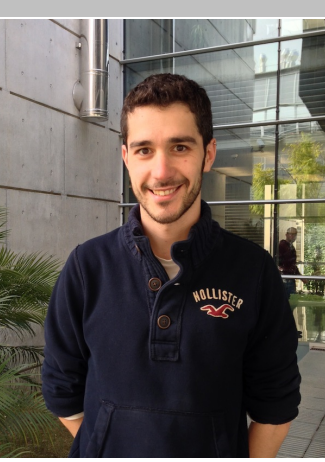
are primarily focused on the field of metal-catalyzed carbon dioxide fixation and $\mathrm{C}-\mathrm{O}$ bond cleavage processes.

Arkaitz Correa studied chemistry at the University of the Basque Country (UPVEHU). He completed his PhD studies in 2006 under the guidance of Prof. Esther Dominguez. Along that time he did a short stay with Prof. Ben L. Feringa at University of Groningen. In 2007 he undertook his first postdoctoral studies with Prof. Carsten Bolm at RWTH-Aachen University (20072008). Subsequently, he joined the group of Prof. Ruben Martin at ICIQ (Tarragona) as a postdoctoral fellow (2008-2010). In

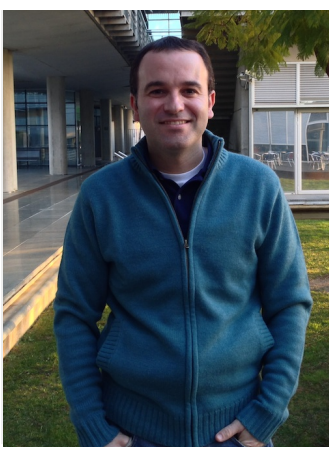

2010 he started a collaborative project with Bayer CropScience at the CSIC under the supervision of Prof. J. M. Lassaletta. In April 2011, he returned to the group of Prof. Ruben Martin at ICIQ as Juan de la Cierva researcher. Recently, he has been awarded with a Ramón y Cajal research contract to continue his research career at UPV-EHU in the Basque Country.

Ruben Martin conducted his undergraduate studies at the University of Barcelona. He then received his $P h D$ in 2003 from the University of Barcelona under the guidance of Prof. Antoni Riera. In 2004, he moved to the Max-Planck Institut für Kohlenforschung as a Humboldt postdoctoral fellow with Prof. Alois Fürstner. In 2005 he then undertook further postdoctoral studies at MIT with Prof. Stephen L. Buchwald as a MEC-Fulbright fellow. In September 2008 he initiated his independent career as an assistant

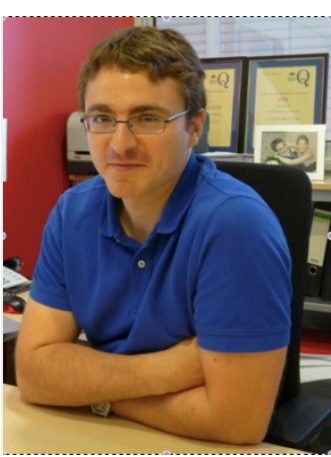
professor at the ICIQ (Tarragona). In July 2013 he was promoted to associate professor and subsequently to ICREA Research Professor. His research is focused on the development of new metal-catalyzed activation of inert bonds. His work has been rewarded, among others, by the RSEQ Sigma-Aldrich prize for Outstanding Emerging Investigators (2010), Thieme Chemistry Award (2011), Eli Lilly Young Investigator Award (2011), and he currently holds a European Research Council (ERC) Starting Grant (2011).

\section{Reductive Coupling Reactions of Unactivated Organic Halides with Carbonyl-type Compounds}

The addition of organolithium or Grignard reagents, among others, to carbonyl compounds has evolved to a mature tool in organic synthesis. ${ }^{[8]}$ While no doubt robust synthetic tools, these methodologies are still limited to the use of stoichiometric amounts of well-defined, and in some cases air- and moisturesensitive organometallic species that are ultimately prepared from the corresponding organic halides. From an ideal perspective, the crucial organometallic species should be generated in situ without the need for using sensitive reagents. Therefore, the means to effect a reductive coupling reaction of organic halides with carbonyl compounds in the presence of a reducing agent will present a considerable amount of attractive features, both from an experimental ease and step-economical standpoint. The successful development of the Barbier reaction could be visualized as the first step towards achieving such goal in which an activated alkyl halide reacts with a carbonyl compound in the presence of simple, inexpensive and water insensitive $\mathrm{Mg}, \mathrm{Zn}, \mathrm{Al}$ or In, among others. ${ }^{[9]}$

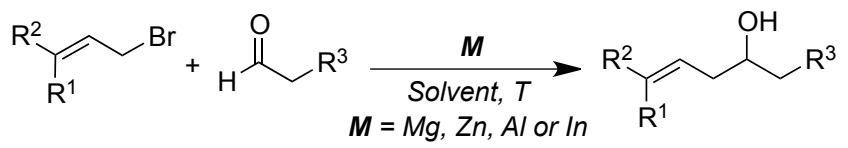

Scheme 2. General scheme for the Barbier reaction of allyl electrophiles

A considerable step forward in Barbier-type reactions was the development of the mild and chemoselective NozakiHiyama-Kishi (NHK) reaction catalytic in $\mathrm{Cr}^{[10]}$ in which activated vinyl or allyl (pseudo)halides react with carbonyl compounds, typically aldehydes, with catalytic amounts of $\mathrm{CrX}_{n}$, $\mathrm{Mn}$ and in the presence of an activating reagent, typically TMSCl. The importance of this reaction is manifested by its prolific use in total synthesis, such as in the impressive total synthesis of palytoxin by Kishi, ${ }^{[11]}$ as well as in pharmaceutical industry. Interestingly, this reaction can be even performed in an enantioselective fashion, ${ }^{[12]}$ providing access to valuable synthetic intermediates from simple precursors.<smiles>[R]CC(O)CC([R])=CC([R])=CC([R])[R]</smiles>

Scheme 3. General scheme for the Cr-catalyzed NHK reaction.

While Barbier-type reactions, including the NHK reaction, have undoubtedly impacted the field of organic chemistry, these reactions are primarily limited to counterparts with a weak $\mathrm{C}-\mathrm{X}$ bond and particularly reactive carbonyl compounds. Therefore, the extension to less activated counterparts have been considered a quest for organic chemists. In line with this notion, Majumdar and Cheng developed a Ni-catalyzed reaction between aryl bromides and aldehydes under reductive conditions to afford secondary alcohols (Scheme 4). ${ }^{[13}$ ] Generally, aromatic carbinols can be obtained in high yields and with good chemoselectivity profile employing the $\mathrm{NiBr}_{2}$ (dppe)/Zn couple. Unfortunately, however, the reaction was limited to the use of particularly activated aromatic aldehydes. While the temperature proved to be important for improving the selectivity of the process, the nature of the ligand played a critical role for sucess; indeed, the reaction only took place at some extent when bidentate phosphines or 
bisoxazolines were employed as ligands. Unfortunately, no stereoselectivity was observed with the use of chiral bisoxazolines as ligands. The authors suggested a mechanism consisting of an initial $\mathrm{Ni}(\mathrm{II})$ to $\mathrm{Ni}(0)$ reduction mediated by $\mathrm{Zn}$ followed by an oxidative addition into the $\mathrm{C}-\mathrm{Br}$ bond (I). Subsequently, it was postulated that the $\mathrm{ZnBr}_{2}$ generated in situ in the initial reduction step acted as a halide scavenger, thus opening up a open coordination site and setting up the stage for binding the aldehyde motif into the metal center (II). ${ }^{[14]}$

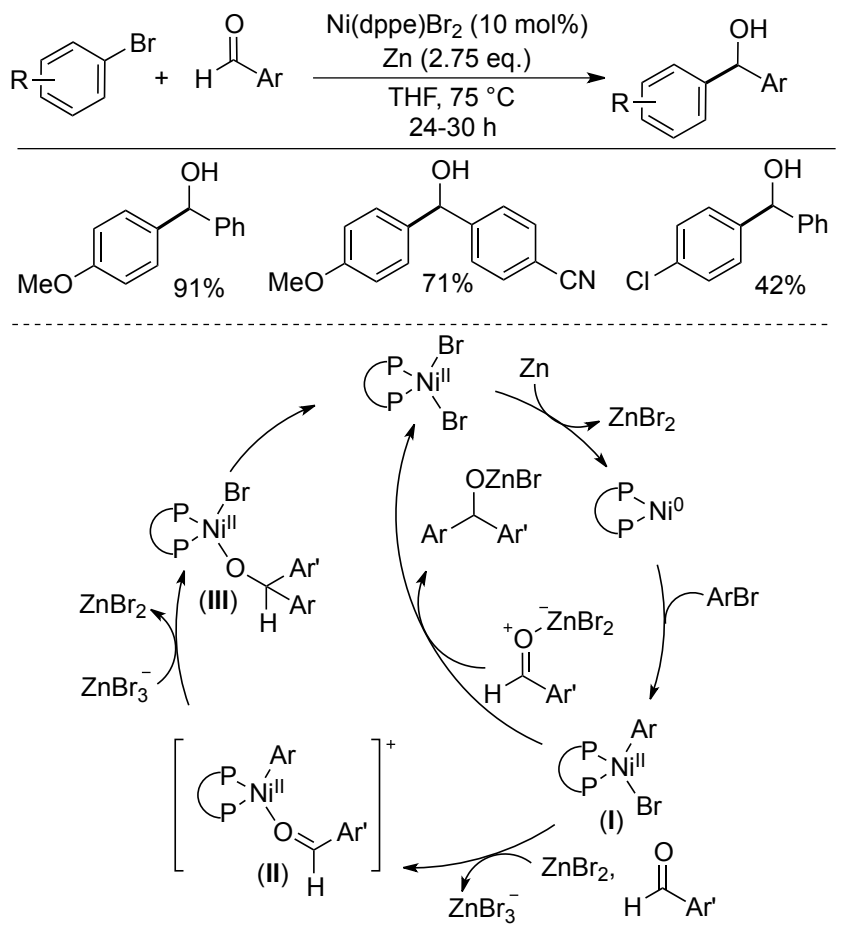

Scheme 4. Ni-catalyzed reductive coupling of aryl bromides with benzaldehydes.

Shortly after, the Cheng group reported a similar procedure for the synthesis of aromatic ketones. ${ }^{[15]}$ Intriguingly, the exact catalyst system previously employed for aryl bromides ${ }^{[13]}$ affords aromatic ketones when aryl iodides are employed as substrates at higher temperatures (Scheme 5 ). In this case, the generality of the reaction was expanded to the use of heterocyclic and aliphatic aldehydes as well. While a similar sequence of events was postulated when employing aryl iodides, the nickel alkoxide VI was believed to undergo $\beta$ hydride elimination to give the aryl ketone and a nickel hydride which, upon reductive elimination recovered the catalytically active $\mathrm{Ni}(0)$ species. Although $\mathrm{Zn}$ was suggested to act as an acid scavenger affording $\mathrm{ZnX} X_{2}$ and $\mathrm{H}_{2}$, no $\mathrm{H}_{2}$ evolution was detected in the reaction mixture. Interestingly, gas release could be observed in the presence of a $\mathrm{Zn} / \mathrm{ZnI}_{2}$ couple.

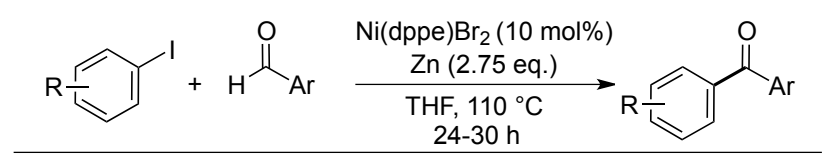

II

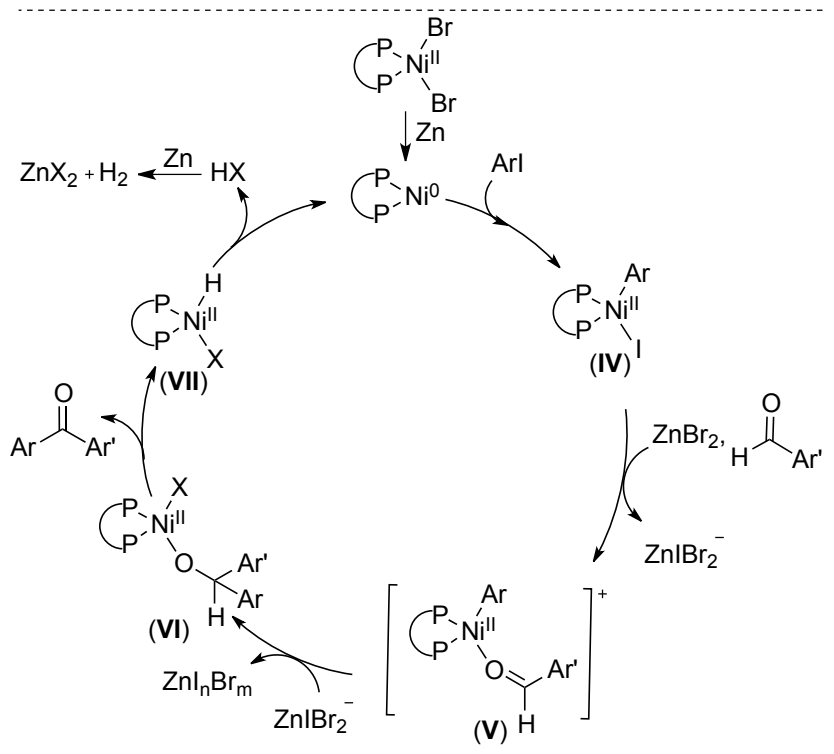

Scheme 5. Ni-catalyzed reductive coupling of aryl iodides with benzaldehydes.

In 2007, Durandetti and co-workers expanded the scope of metal-catalyzed reductive coupling of aryl halides beyond the use of aldehydic counterparts for the synthesis of $\beta$ hydroxyesters in a Reformatsky-type reaction. ${ }^{[16]}$ The authors demonstrated that ketones could also be employed as coupling partners by using nickel catalysis and manganese as reducing agent. More recently, Jia and Gao discovered a Ni-catalyzed intramolecular addition of aryl or vinyl halides to ketamides for preparing 3-hydroxyoxindoles (Scheme 6). ${ }^{[17]}$ In sharp contrast with Cheng's observations, ${ }^{[13,15]}$ monodentate and rather bulky $\mathrm{PC}_{3}$ provided the best results, with $\mathrm{ZnMe}_{2}$ being used as the reducing agent. Unlike Chen's procedure, ${ }^{[13,15]}$ the method allowed for the coupling of rather challenging aryl chlorides, an observation that might be tentatively attributed to the use of bulky and electron-rich $\mathrm{PCy}_{3} \cdot{ }^{[1 f]}$ As for many other reductive catalytic events, ${ }^{[5]}$ the need for Zn-reagents might suggest the intermediacy of organozinc species that are responsible for the observed reactivity. Control experiments, however, evidenced that arylzinc species were not competent as reaction intermediates. This observation was fostered by the nonnegligible enantioselectivity observed (up to $37 \%$ e.e.) when a chiral phosphoramidite ligand was used.

While aldehydes and ketones can be successfully coupled in catalytic reductive coupling reactions with great efficiency, other types of carbonyl-type compounds have also proven to be suitable substrates. The considerably higher reactivity of acid chlorides as compared with other carbonyl compounds makes them ideal coupling partners in reductive coupling events. Gosmini et al. discovered that acid chlorides could be utilized, for the first time, in reductive coupling events of aryl bromides mediated by $\mathrm{Zn}$ and in the presence of catalytic amounts of $\mathrm{ZnBr}_{2}$ and $\mathrm{CoBr}_{2}$ for preparing aromatic ketones (Scheme 7). ${ }^{[18]}$ The suggested mechanism is based on the ability of $\mathrm{Co}(\mathrm{I})$ species to trigger an initial oxidative addition to the acyl-Cl 
bond in order to produce a rather elusive $\mathrm{Co}$ (III) intermediate (VIII). This proposed mechanism is somewhat reminiscent of a number of elegant electrochemical methods reported in the literature for similar means. ${ }^{[19]} \mathrm{A}$ final transmetallation (IX) and reductive elimination was postulated to afford the desired product while recovering the catalytically active $\mathrm{Co}(\mathrm{I})$ species. $^{[20]}$

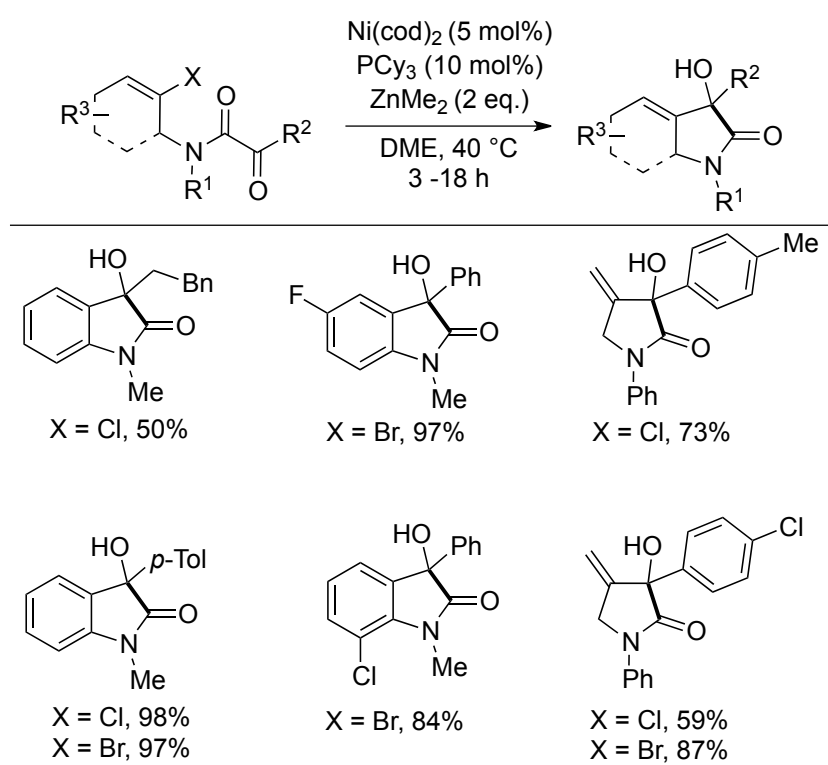

Scheme 6. Ni-catalyzed intramolecular reductive coupling of aryl bromides and chlorides with ketamides.

Although no doubt innovative, this methodology requires the use of stoichiometric amounts of organometallic, and pyrophoric compounds, hence significantly limiting its synthetic utility. A more direct reductive carbonylation using acid chlorides has been recently developed by Gong and co-workers in which unactivated alkyl halides could be used as coupling partners (Scheme 8). ${ }^{[21]}$ Primary and sterically-encumbered secondary alkyl iodides were efficiently coupled with $\mathrm{Ni}$ precatalysts in combination with phenantroline-type ligands (L1). Not surprisingly, much less reactive alkyl bromides were not effective, obtaining the expected product in moderate yields. The utility of this methodology was expanded with the development of a one-pot reaction from benzoic acids to afford differently substituted aromatic ketones, thus constituting a powerful alternative to the use of organolithium derivatives for similar purposes. Furthermore, the reaction could easily be scaled up without compromising the yield. ${ }^{22}$ ] Control experiments determined that formation of organozinc intermediates was kinetically disfavoured and that the reaction takes place via a distinctive mechanistic scenario. Given the known ability of $\mathrm{Ni}$ catalysts to promote Negishi-type couplings, ${ }^{[23]}$ the authors suggested that the mechanism was based on a $\mathrm{Ni}(\mathrm{I}) / \mathrm{Ni}(\mathrm{III})$ couple. ${ }^{[24]}$ In this manner, it was believed that $\mathrm{Ni}(\mathrm{I})$ triggers the formation of alkyl radicals with concomitant formation of $\mathrm{Ni}$ (II) species. A radical recombination afforded $\mathrm{Ni}(\mathrm{III})$ species that were subsequently reduced to $\mathrm{Ni}(\mathrm{I})$ by $\mathrm{Mn}$. Oxidative addition of the latter to the acid chloride motif and reductive elimination yielded the desired ketone while regenerating the initial $\mathrm{Ni}(\mathrm{I})$ species.
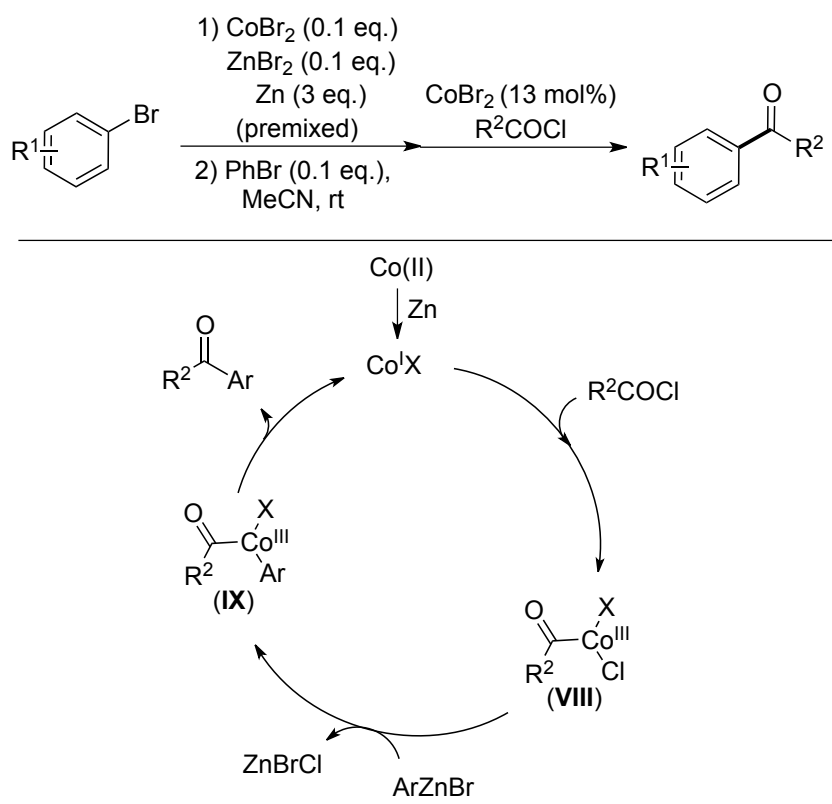

Scheme 7. Mechanism for the Co-catalyzed reductive coupling of aryl bromides with acid chlorides via the in situ generation of organozinc species.

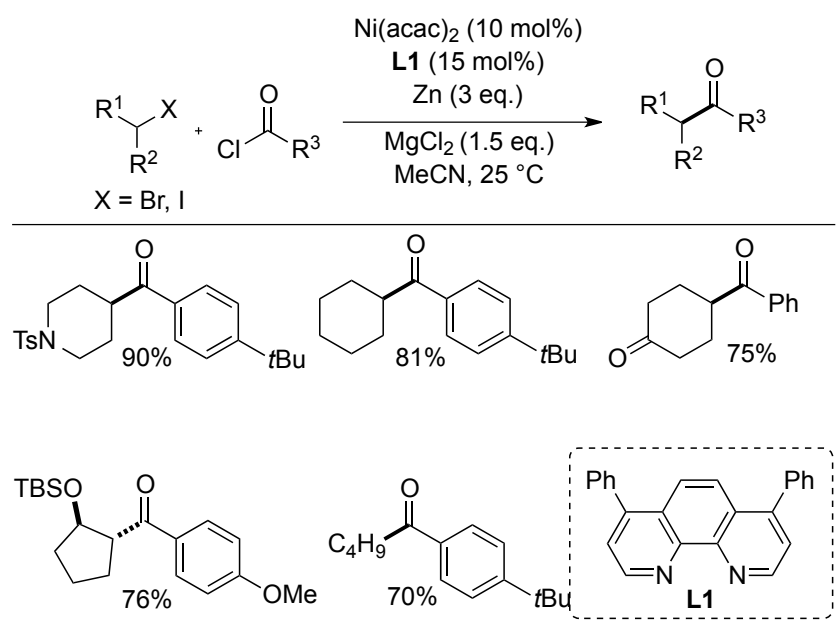

Scheme 8. Ni-catalyzed reductive coupling of alkyl halides with acyl chlorides.

A more suitable methodology for the synthesis of dialkyl ketones was developed by Weix and co-workers using $\mathrm{Ni}$ catalysts (Scheme 9). ${ }^{[25]}$ In this case, 4,4'-di-tert-butyl-2,2'bipyridine (dtbpy, L2) allowed for the coupling of primary and secondary alkyl iodides with acid chlorides or thioesters (Scheme 9). The reaction displayed a remarkable functional group tolerance and even highly hindered ketones could be obtained in good yields. However, low yields were usually obtained with aromatic acid chlorides, showing the limitations of this strategy. A slightly different mechanism was proposed for this reaction. Prompted by the work of Yamamoto, ${ }^{[2]}$ the authors hypothesized that the in situ generated $\mathrm{Ni}(\mathrm{II})$ oxidative addition species $(\mathbf{X})$ could disproportionate to give intermediates $\mathbf{X I}$ and $\mathbf{X I I}$. While the reduction of XII promoted by $\mathrm{Mn}$ would regenerate the initial $\mathrm{Ni}(0)$ species, intermediate $\mathbf{X I}$ could transfer the alkyl residue into the acid chloride motif. It is worth noting that such mechanistic scenario is significantly different from commonly proposed pathways within the realm of Ni-catalyzed reductive cleavage reactions. ${ }^{[5]}$ Unfortunately, however, an in depth mechanistic study was not performed to lend support for disproportionation events within the catalytic 
cycle. Although tentative, we speculate that such scenarios might come into play for related reductive cross-coupling events.
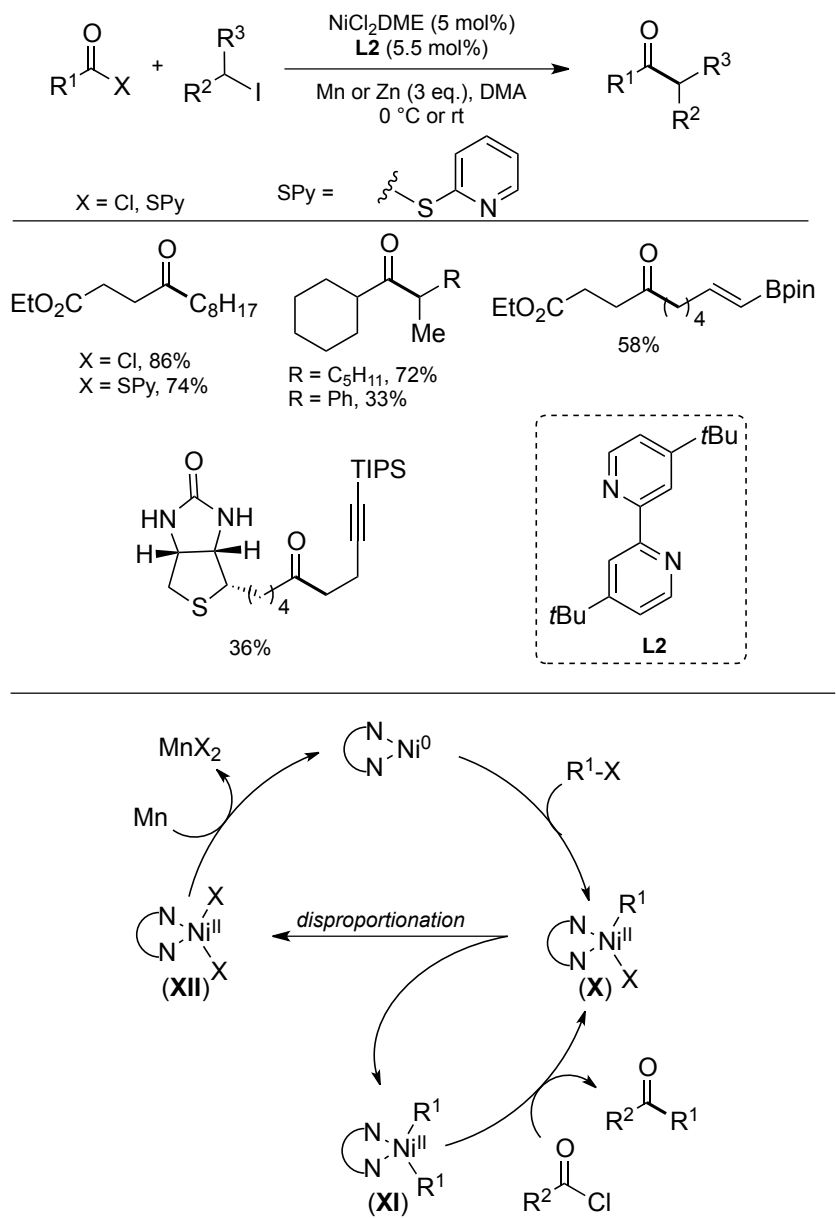

Scheme 9. Ni-catalyzed cross-coupling reaction of acid chlorides with secondary alkyl halides.

Reisman and co-workers recently reported an excellent contribution to the field of metal-catalyzed reductive cleavage of organic halides and carbonyl-type compounds (Scheme 10). ${ }^{[27]}$ Particularly, the authors designed an enantioconvergent reductive coupling of acid chlorides with activated benzyl halides. While a variety of chiral ligands were tested, the use of a chiral bisoxazoline ligand (L3) provided the best results with enantioselectivities up to $94 \%$ and with an excellent chemoselectivity profile. Interestingly, it was revealed that the inclusion of additives such as benzoic acids was crucial; in line with the same notion, a delicate balance between reactivity and stereoselectivity can be attained with the use of mixed solvent mixtures. The mechanism of the reaction was believed to proceed via a $\mathrm{Ni}(\mathrm{I}) / \mathrm{Ni}(\mathrm{III})$ couple (Scheme 10). After initial oxidative addition into the acid chloride motif, a reduction promoted by $\mathrm{Mn}$ would result in XIV. ${ }^{[24]}$ Subsequently, an oxidative addition into the $\mathrm{C}-\mathrm{Cl}$ bond of the benzylic framework via an stereoconvergent radical recombination would afford $\mathbf{X V I}$, setting up the stage for a reductive elimination en route to the desired coupling product. A final reduction promoted by $\mathrm{Mn}$ would regenerate the active $\mathrm{Ni}(0)$ species. Although not contemplated by the authors, one might have envisioned an alternate pathway consisting of the in situ formation of ketenes that would react with the corresponding alkyl halide in a reductive cross-coupling event.
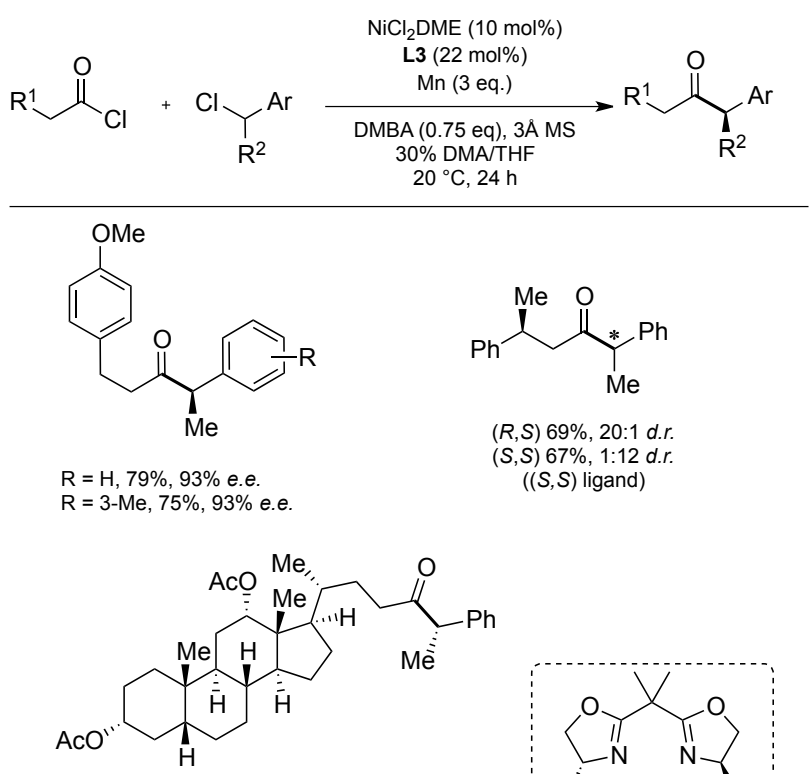

$64 \%, 14: 1$ d.r. $((S, S)$ ligand $)$
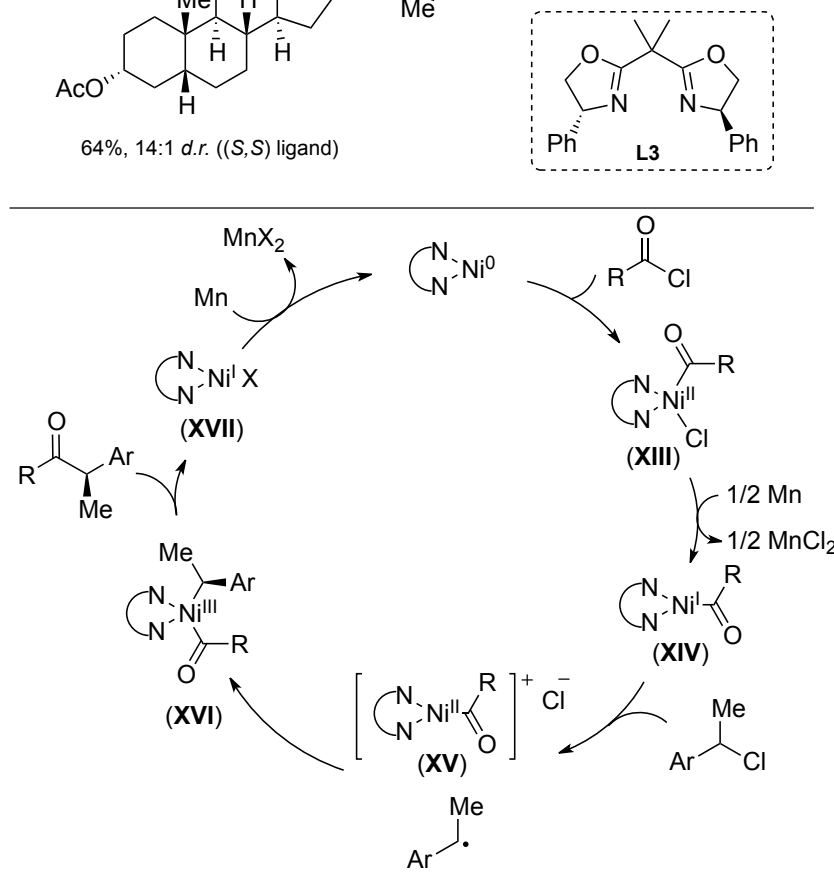

Scheme 10. Ni-catalyzed enantioselective reductive coupling of benzyl chlorides with acid chlorides.

Following their interest in Co-catalyzed reductive crosscoupling reactions, ${ }^{[18]}$ Gosmini and co-workers discovered that a range of aryl bromides could also be efficiently coupled with acid anhydrides. ${ }^{[28]}$ In contrast with the use of acid chlorides (Scheme 7), ${ }^{[18]}$ the diminished reactivity of acid anhydrides allowed the reaction to be performed in one pot (Scheme 11). In this case, allyl chloride was required as additive to enhance the formation of the organozinc species and reduce the formation of undesired byproducts. Control experiments demonstrated that $\mathrm{CoBr}_{2}$ might serve as a precatalyst en route to the catalytically active Co(I) species. ${ }^{[24]}$ While the efficiency of the reaction was strongly dependent on the nature of the anhydride (with alkyl substituents giving the best results), the substitution pattern on the aromatic bromide also had also an effect on the reaction outcome, an observation that was corroborated by a Hammett study. 


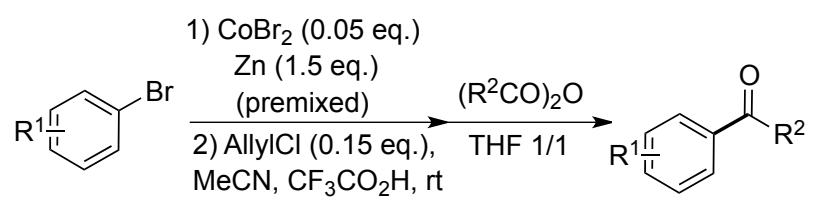

$\overbrace{79 \%}^{\left(C_{C_{4} \mathrm{H}_{9}}^{O}\right.}$<smiles>COc1ccccc1C(C)=O</smiles>

$72 \%$

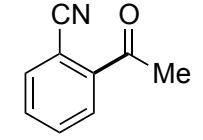

$34 \%$<smiles>CC(=O)c1ccccc1C(F)(F)F</smiles>

$71 \%$
Scheme 11. Co-catalyzed reductive coupling reaction of aryl bromides with acid anhydrides via the in situ generation of organozinc species.

More recently, the Ni-catalyzed reductive coupling reaction of acid anhydrides was extended to the use of unactivated alkyl halides as coupling partners. ${ }^{[29]}$ Lin and Gong showed that alkyl iodides and alkyl bromides could be efficiently coupled with a variety of acid anhydrides using $\mathrm{Ni}(\operatorname{cod})_{2}$ as the catalyst in combination with phenanthroline-type ligands (L4 and L5), $\mathrm{MgCl}_{2}$ as an additive and $\mathrm{Zn}$ as reducing agent in acetonitrile at room temperature (Scheme 12). The $\mathrm{MgCl}_{2}$ was believed to play with dual roles, both as a Lewis acid activating the anhydride motif and as a salt scavenger in the $\mathrm{Zn}$ surface. Although the reaction was general for both primary and secondary alkyl halides, it was found that cyclic secondary alkyl halides gave the best results. Interestingly, good yields were obtained regardless of the nature of the anhydride employed. Furthermore, the authors demonstrated the practicality of the method by generating the acid anhydride in situ from the corresponding carboxylic acid and Boc anhydride, albeit larger quantities of the latter were required. Although initial experiments demonstrated that a Negishi-type pathway via the intermediacy of organozinc species may be operative using alkyl iodides, the authors did not support such scenario when alkyl bromides were employed. In this case, it was postulated that the reaction proceeded via $\operatorname{ArCONi(II)~species~that~}$ subsequently reacted with the corresponding alkyl bromide.

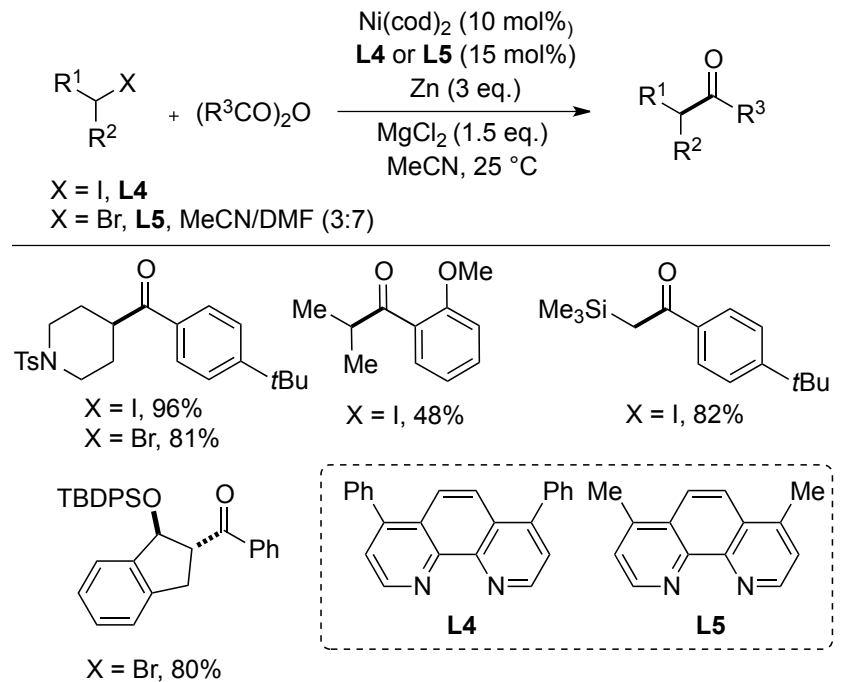

Scheme 12. Ni-catalyzed reductive coupling of unactivated alkyl halides with acid anhydrides.

In 2005, the use of isocyanates as coupling partners under catalytic reductive conditions was developed by Hsieh and Cheng for the formation of imide and amide derivatives. ${ }^{[30]}$ The catalytic protocol was based on the use of $\mathrm{Ni}(\mathrm{dppe}) \mathrm{Br}_{2}$ employing $\mathrm{Zn}$ as final reductant (Scheme 13). While the presence of catalytic amounts of $\mathrm{NEt}_{3}$ was found to accelerate the reaction, the inclusion of dppe significantly decreased the amounts of homocoupling products in the intramolecular approach. While in depth mechanistic studies were not performed, the authors favoured a pathway consisting of an oxidative addition of a $\mathrm{Ni}(0)$ to the corresponding iodoarene followed by a migratory insertion into the isocyanate motif. Intriguingly, the intermolecular reaction was better conducted with aryl bromides in the absence of $\mathrm{NEt}_{3}$ since iodobenzene derivatives primarily resulted in homocoupling products.

Prompted by a seminal work of Larock using $\mathrm{Pd}$ catalysts, ${ }^{[31]}$ Hsieh et al. described an intermolecular catalytic coupling of aryl halides with aromatic and aliphatic nitrile derivatives using $\mathrm{Ni}$ catalysts and $\mathrm{Zn}$ as reductant (Scheme 14). ${ }^{[32]}$ Optimization studies revealed that the bidentate nature of the phosphine ligand utilized and the $\mathrm{Ni}$ source were absolutely crucial for success, with dppp and $\mathrm{NiCl}_{2} \cdot \mathrm{DME}$ providing the best results. However, the presence of electrondonating or electron-withdrawing groups on the aryl iodide had a negative impact on reactivity. Likewise, the inclusion of orthosubstitution significantly lower the efficiency of the process, thus showing the inherent limitations of this method. Although the use of tertiary aliphatic nitriles did not lead to the formation of products, a wide range of secondary nitriles could be successfully employed using this approach. A plausible mechanism involved an oxidative addition of an in situ generated $\mathrm{Ni}(0)$ into the $\mathrm{C}-\mathrm{I}$ bond of the iodoarene, followed by coordination and insertion of the cyano group. The resulting cationic species might undergo reductive elimination en route to an iminonickel(II) intermediate. A final hydrolysis delivered the product and recovered back the $\mathrm{Ni}(\mathrm{II})$ precatalyst.

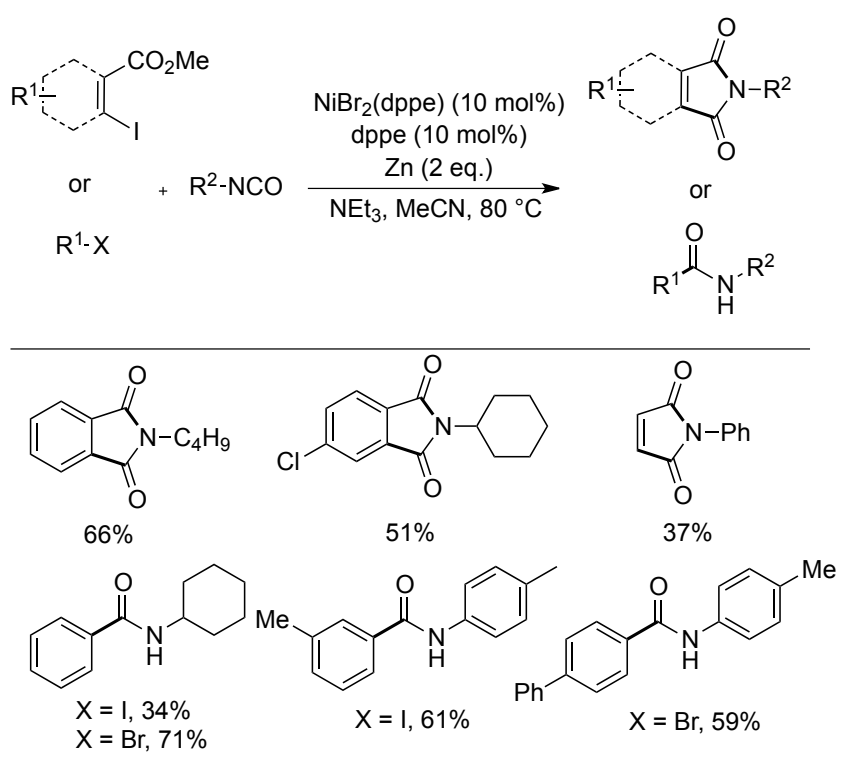

Scheme 13. Ni-catalyzed reductive coupling of haloarenes with isocyanates. 


$$
\begin{gathered}
\begin{array}{c}
\mathrm{NiCl}_{2} \operatorname{DME}(10 \mathrm{~mol} \%) \\
\mathrm{dppp}(10 \mathrm{~mol} \%), \\
\mathrm{Zn}(2 \mathrm{eq} .), \mathrm{H}_{2} \mathrm{O}(1.2 \mathrm{eq} .)
\end{array} \\
\begin{array}{c}
\mathrm{DME} \\
100^{\circ} \mathrm{C}, 36 \mathrm{~h}
\end{array}
\end{gathered}
$$<smiles>O=C(c1ccccc1)c1ccccc1Cl</smiles>

$78 \%$<smiles>O=C(Cc1ccc2c(c1)OCO2)c1ccccc1</smiles>

$76 \%$<smiles>O=C(c1ccccc1)C1CCCCC1</smiles>

$86 \%$<smiles>Cc1ccccc1C(=O)Cc1cccc2ccccc12</smiles>

$55 \%$<smiles>Cc1ccc(C(=O)Nc2ccccc2)cc1</smiles>

Scheme 14. Ni-catalyzed reductive coupling of iodoarenes with nitriles.

Zhang, Wang and co-workers have recently established an unconventional strategy for the reductive cross-coupling reaction of aryl bromides with $\mathrm{N}$-tosylhydrazones to prepare synthetically relevant triarylmethane derivatives (Scheme 15). ${ }^{[33]}$ This approach required the use of $\mathrm{Pd}$ catalysts in combination with ammonium formate as reducing agent. The use of a phosphine ligand (L6), tert-pentanol as solvent, and ammonium acetate as additive provided the best results while minimizing the formation of reduced arenes. Under these optimized conditions, a wide range of differently substituted $\mathrm{N}$ tosylhydrazones and aryl bromides were tolerated, and only the introduction of heteroaromatic substituents or ortho-substituted aryl bromides hampered the reaction. The mechanism suggested for this transformation was believed to proceed via initial reduction of $\mathrm{Pd}(\mathrm{OAc})_{2}$ to $\mathrm{Pd}(0)$ promoted by ammonium formate followed by oxidative addition to the aryl bromide to afford an arylpalladium(II) intermediate (XVIII). The latter reacts with a diazo compound formed in situ to deliver a palladium (II) carbene species (XIX). A subsequent [1,2]-aryl migration into the palladium carbene afforded an intermediate $\mathbf{X X}$ that reacted with formate to release $\mathrm{CO}_{2}$ with concomitant formation of a $\mathrm{Pd}$ (II) hydride $\mathbf{X X I}$ that ultimately resulted in the final product by a final reductive elimination event.
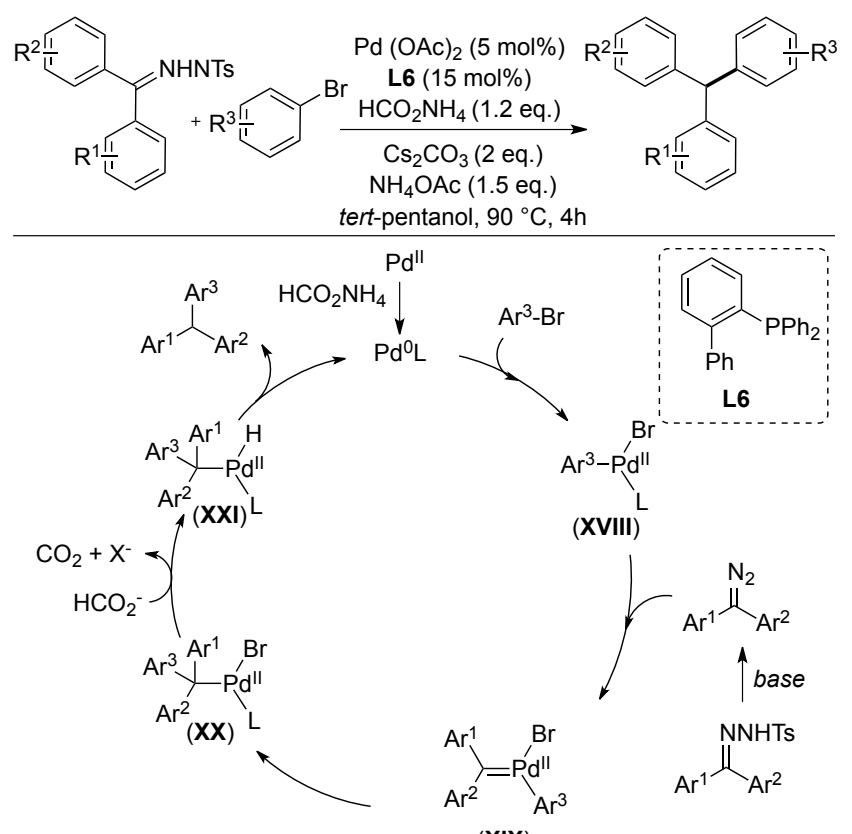

(XIX)
Scheme 15. Mechanism of the Pd-catalyzed reductive synthesis of triarylmethanes.

Recently, Weix and co-workers reported an extensive investigation on the reductive cross-coupling reaction of aryl halides with enones as electrophiles to afford substituted silyl enol ethers (Scheme 16). ${ }^{[34]} \mathrm{A}$ broad screening of ligands revealed that the use of neocuproine (L7) or bipyridine allows the use of aromatic halides as electrophilic coupling partners with cyclic and non-cyclic enones. The reaction proceeds with low catalyst loadings ( $1 \mathrm{~mol} \%$ ), a remarkable finding taking into account the typical high loadings required in $\mathrm{Ni}$-catalyzed reductive cleavage events. ${ }^{[5]}$ Several chlorosilanes were also tested, with TESCI giving the best results. The authors favored a mechanism consisting of an oxidative addition into the enone backbone (XXII) followed by reaction with the corresponding aromatic halide to furnish the desired silyl enol ether and a $\mathrm{Ni}(\mathrm{II})$ species (XXIII) that is further reduced to the propagating $\mathrm{Ni}(0)$ species by $\mathrm{Mn}$. While the previous methodology was robust enough to accommodate a series of aryl halides, the extension of alkyl halides has only been accomplished recently by the Weix's group. ${ }^{[35]}$ In this case, the use of a bulky terpyridine (L8) was crucial for the minimization of dimer adducts. The reaction proceeds with moderate-to-good yields and is general for different chlorosilanes. Likewise, secondary and even tertiary unactivated iodo- and bromoalkanes could be utilized. Furthermore, the authors demonstrated that this reaction could be carried out in gram-scale (up to $10 \mathrm{mmol}$ ). Unfortunately, the use of chloroalkanes resulted in the formation of the homocoupling product.
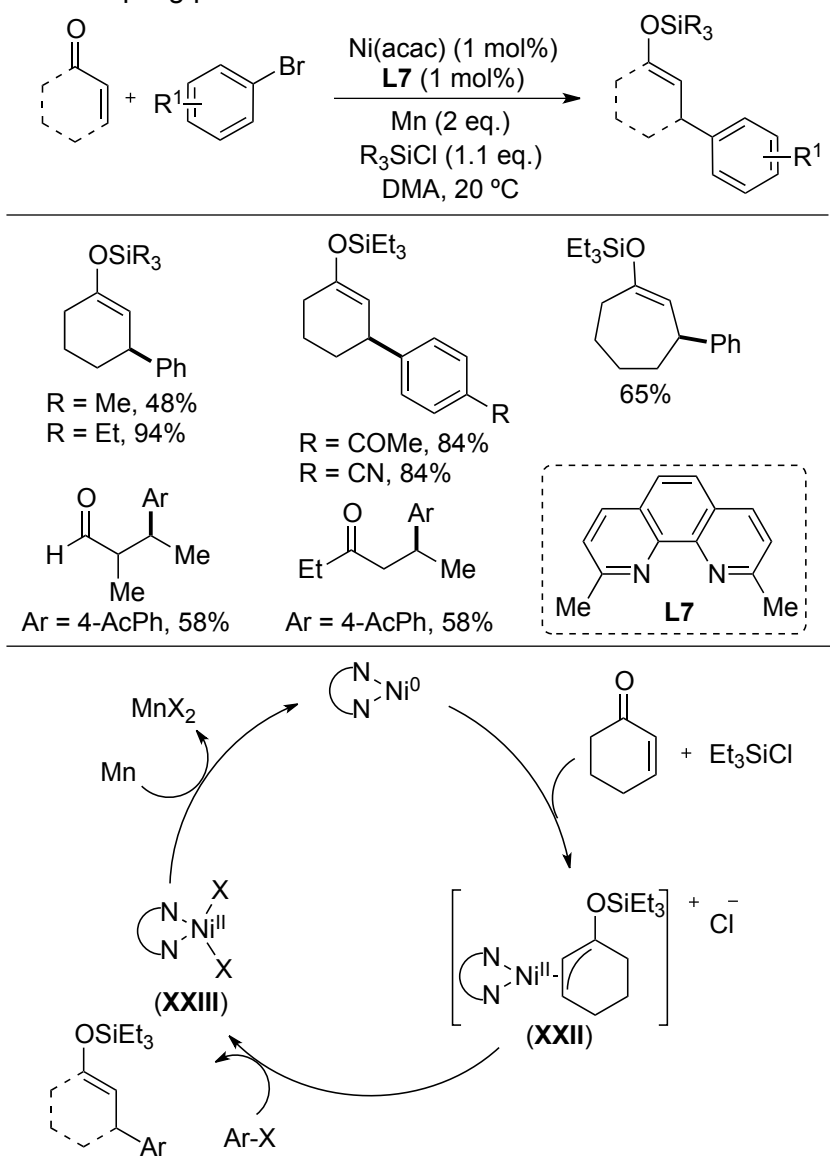

Scheme 16. Ni-catalyzed conjugate addition of aromatic halides to enones. 

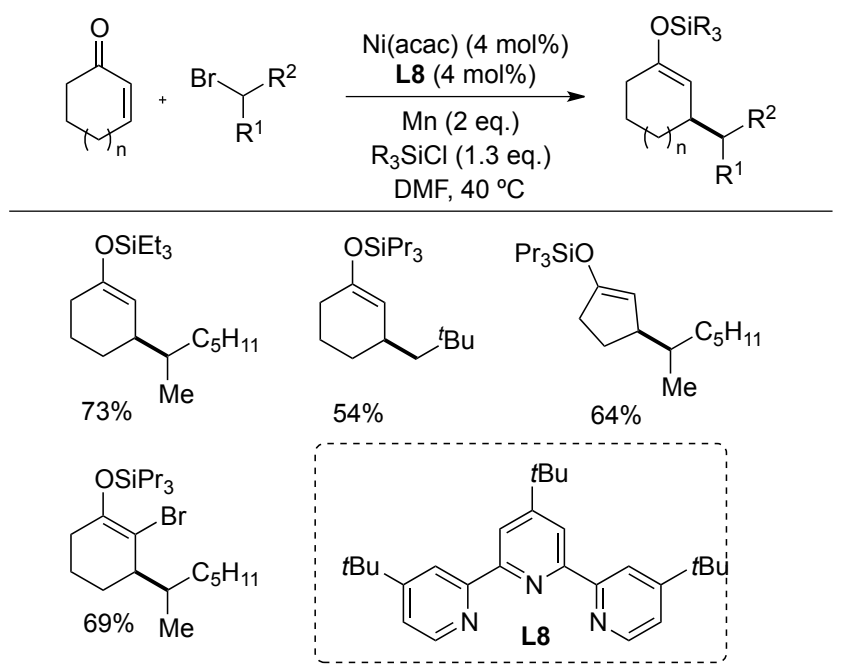

Scheme 17. Ni-catalyzed conjugate addition of secondary halides to enones

Beyond any reasonable doubt, the recent developments in the area of metal-catalyzed reductive coupling reactions of organic halides with carbonyl-type compounds will set the standards for the discovery of more challenging scenarios within this field of expertise. Despite the advances realized, the means to promote asymmetric transformations via metalcatalyzed reductive coupling events has virtually been unexplored with the exception of the elegant work by Reisman. ${ }^{[27]}$ Therefore, it is tempting to speculate that further improvements in this area will probably be focused within the realm of asymmetric catalysis, thus opening up new horizons to be implemented in this relatively unexplored area of research.

\section{Reductive Carbonylation Reactions}

Carbonylation reactions with gaseous carbon monoxide (CO) are key industrial processes for the atom-efficient introduction of $\mathrm{C} 1$ units into organic backbones en route to valuable synthetic intermediates such as aldehydes, alcohols and carboxylic acid derivatives, compounds of utmost importance in pharmaceuticals and agrochemicals. ${ }^{[36]}$ Over the last years, a wide variety of classical palladium-catalyzed carbonylation processes have been described using organic halides as substrates en route to aryl ketone or benzamides, allowing the use of $\mathrm{CO}$ as a readily available feedstock. ${ }^{[36]}$ These reactions follow a common mechanistic scenario consisting of the intermediacy of $\sigma$-acylpalladium species resulting from a $\mathrm{CO}$ insertion into $\sigma$-arylpalladium species (Scheme 18). Subsequently, such intermediates are intercepted by an in situ treatment with different nucleophiles such as alcohols, amines or even carbon nucleophiles such as boronic acids or alkynes, among others (Scheme 18, bottom left). ${ }^{[36]}$ While structurally related, a reductive carbonylation event constitutes a more challenging process since the presence of hydride donors might result in hydrogenolysis of the organic halide via reduction of the intermediate oxidative addition species (Scheme 18, bottom right). If successful, such a method might represent a straightforward and practical alternative, particularly in industry, to the classical synthesis of formyl derivatives based on the treatment of stoichiometric amounts of organometallic species with dimethylformamide.

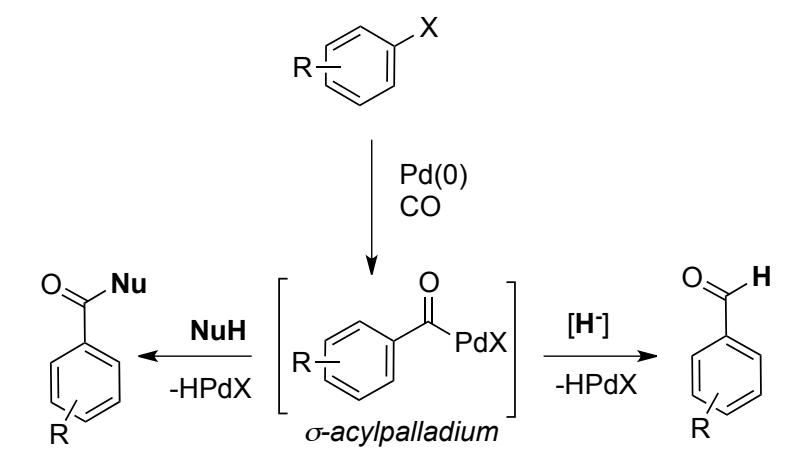

$\mathrm{NuH}=\mathrm{ROH}, \mathrm{H}_{2} \mathrm{O}$,

$\mathrm{RNH}_{2}, \mathrm{ArB}(\mathrm{OH})_{2}$, etc

Reductive Carbonylation

Scheme 18. Pd-catalyzed carbonylation reactions.

In 1974, Heck and co-workers reported the first palladiumcatalyzed reductive carbonylation of aryl and vinyl halides with gaseous $\mathrm{CO}$ utilizing hydrogen as reducing agent. ${ }^{[37}$ ] Unfortunately, such seminal discovery was conducted at high pressures (80-100 bar) and temperatures $\left(80-150^{\circ} \mathrm{C}\right)$ and large amounts of catalyst were required, hence limiting its synthetic application profile. Prompted by such precedents, many research groups described milder alternatives utilizing other hydride sources such as tributyltin hydride $\left(\mathrm{Bu}_{3} \mathrm{SnH}\right),{ }^{[38]}$ organosilanes $^{[39]}$ and particularly attractive and readily available formate salts. ${ }^{[40]}$ In 2006, Beller reported a rather general and highly efficient catalytic reductive carbonylation that used a catalytic system based on $\mathrm{Pd}(\mathrm{OAc})_{2}$ as the precatalyst and di-1adamantyl-n-butylphosphine ( $n \mathrm{BuPAd}_{2}$, CataCXium $\left.\mathrm{A}\right)$ as the ligand (Scheme 19). ${ }^{[41]}$ Interestingly, the scope of the reaction included the coupling of (hetero)aryl and vinyl bromides by using simple and advantageous Syngas $\left(\mathrm{CO} / \mathrm{H}_{2}\right.$ 1:1) at lower pressures ( 5 bar) together with TMEDA as base at $100{ }^{\circ} \mathrm{C}$. Remarkably, these processes were performed on multigram scale for the synthesis of aromatic aldehydes. They further studied in detail the reaction mechanism and unambiguously characterized relevant palladium complexes that suggested a scenario consisting of an oxidative addition, which was found to be rate-determining, followed by $\mathrm{CO}$ insertion into the $\mathrm{Pd}-\mathrm{C}$ bond and subsequent hydrogen transfer aided by the base to deliver the targeted benzaldehyde. ${ }^{[42]}$ 


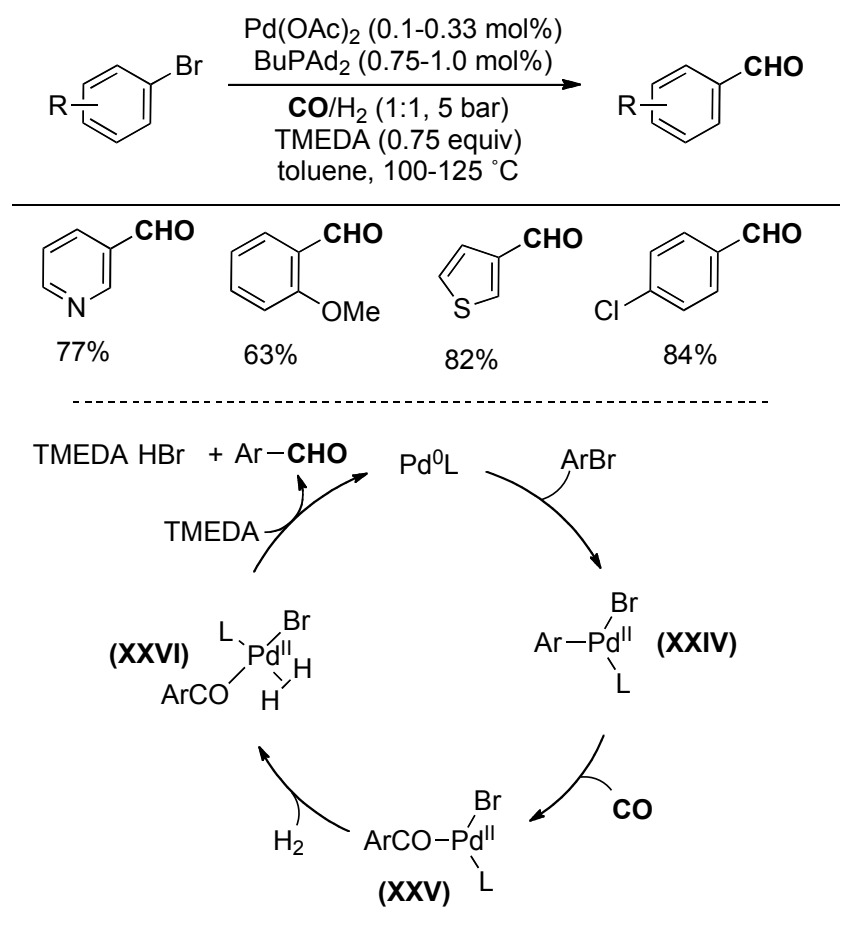

Scheme 19. Pd-catalyzed reductive carbonylation of aryl halides.

While a significant step forward, the use of rather expensive and air-sensitive $n \mathrm{BuPAd}_{2}$ constituted a serious drawback to be overcome. Preliminary studies from Beller and co-workers revealed that the topology of the phosphine-type ligand had a crucial impact on the reaction outcome $;^{[41,42]}$ while the replacement of the adamantyl units in $n \mathrm{BuPAd}_{2}$ by tert-butyl groups had little influence on reactivity, the use of $\mathrm{PtBu}_{3}$ resulted in no conversion to products. ${ }^{[41,42]}$ In line with these observations, they described a new protocol for the reductive carbonylation of aryl and heteroaryl bromides based on the use of cheaper and easy-to-handle di-tert-butylphosphinite ligands with Syngas (5 bar) at $100{ }^{\circ} \mathrm{C} \cdot{ }^{[43]}$ Unlike the former protocol based upon $n \mathrm{BuPAd}_{2}$ that exhibited a wide substrate scope, this new catalyst system was found inefficient when coupling particularly challenging 3-bromopyridine and sterically hindered substrates such as mesityl bromide. An additional bonus of this method came from the observation that $(t \mathrm{Bu})_{2} \mathrm{PCl}$ can be used as a surrogate of the corresponding di-tert-butylphosphinite by in situ treatment with TMEDA in $n$-propanol.

With the aim of designing new cost-efficient catalyst that enhance the synthetic utility of the reductive carbonylation of aryl halides, Nagarkar and co-workers reported an alternate protocol involving a combination of $\mathrm{Pd}(\mathrm{acac})_{2}$ and commercially available and bench stable 1,1-bis(diphenylphosphino)methane (dppm) as supporting ligand. ${ }^{[4]}$ Under these conditions, the formylation of certain aryl and heteroaryl iodides occurred smoothly at $100{ }^{\circ} \mathrm{C}$ with Syngas (10 bar). In this case, 3iodopyridine was successfully formylated; unfortunately, 2iodothiophene and aryl iodides bearing electron-withdrawing substituents exhibited poor reactivity. It is worth noting, however, that this method relied on the use of comparatively more expensive aryl iodides as coupling partners; indeed, the use of aryl bromides was found to be highly inefficient for their purposes.

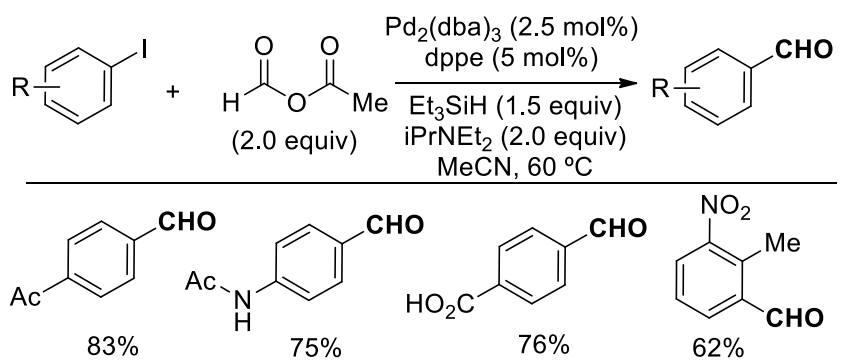

Scheme 20. Use of mixed anhydride as $\mathrm{CO}$ source in $\mathrm{Pd}$-catalyzed reductive carbonylation reactions.

Owing to the high toxicity of $\mathrm{CO}$ and the requirement for high-pressure equipment in many instances, a number of more practical and advantageous CO-free carbonylation reactions have been developed. In 2004 Cacchi and co-workers devised a Pd-catalyzed reductive carbonylation of aryl iodides utilizing a thermally unstable mixed anhydride derived from acetic and formic acid as carbonylation source and $\mathrm{Et}_{3} \mathrm{SiH}$ as reducing agent (Scheme 20). ${ }^{[45]}$ They found that the use of $\mathrm{Pd}_{2}(\mathrm{dba})_{3}$ in combination with 1,1-bis(diphenylphosphino)ethane (dppe), $\mathrm{Pr}_{2} \mathrm{EtN}$ as base in $\mathrm{CH}_{3} \mathrm{CN}$ at $60{ }^{\circ} \mathrm{C}$ led to the conversion of a wide variety of aryl iodides with different electronic environments into the corresponding benzaldehydes. The formylation of electron-poor aryl iodides was conducted in DMF in the presence of 3.0 equivalents of $\mathrm{LiCl}$; the use of such additive, however, is not totally understood, although cation solvation might likely play a role.

In 2013, Manabe and co-workers introduced the use of $N$ formylsaccharin as a cheap and easy-to-handle $\mathrm{CO}$ source in the Pd-catalyzed reductive carbonylation of aryl bromides with $\mathrm{Et}_{3} \mathrm{SiH}$ as reducing agent (Scheme 21). ${ }^{[4]}$ This CO surrogate was first developed by the group of Cossy and applied as a formylating agent of amines. ${ }^{[47]}$ Control experiments verified that the decarbonylation of $\mathrm{N}$-formylsaccharin to in situ produce $\mathrm{CO}$ and saccharin quantitatively occurred within $30 \mathrm{~min}$ in the presence of a mild base such as $\mathrm{Et}_{3} \mathrm{~N}$ or $\mathrm{Na}_{2} \mathrm{CO}_{3}$. Interestingly, the process was not strongly ligand-dependent as compared with previous reductive carbonylations for similar means. ${ }^{[41,44]}$ In this respect, a variety of bidentate phosphines showed excellent activity being 1,1-bis(diphenylphosphino)buthane (dppb) the ligand of choice for evaluating the preparative scope of the process. The method was efficient for the formylation of a wide range of aryl and heteroaryl bromides at $65-90{ }^{\circ} \mathrm{C}$ under low catalyst loadings, and in the presence of sensitive functional groups. Although some ortho substituted aryl bromides underwent the desired cross-coupling reaction, the extension to more sterically-demanding 2,6-disubstituted aryl bromides was unfruitful. Whereas the use of aryl iodides provided similar results, aryl triflates showed comparatively lower reactivity. Regarding the reaction mechanism, the authors hypothesized that an alternate pathway to the commonly accepted route involving the trapping of acylpalladium species by $\mathrm{Et}_{3} \mathrm{SiH}$ may be operative. In order to shed light into the mechanism, several tests were conducted, indicating the following: (a) the use of $N$ benzoylsaccharin under the optimal reaction conditions provided benzaldehyde in 64\% HPLC yield; (b) formation of acylsaccharin was confirmed by HRMS analysis when using 2bromonaphthalene as substrate, and it could be trapped by addition of $n \mathrm{BuOH}$ to deliver the corresponding $n$-butyl ester. In line with these observations, a plausible catalytic cycle was suggested (Scheme 21, bottom) in which a ligand exchange occurred from $\mathbf{X X V I I I}$ with in situ formed saccharin en route to $\mathbf{X X I X}$ that might be in equilibrium with $\mathbf{X X X}$ (path a). Final 
hydride transfer from $\mathrm{Et}_{3} \mathrm{SiH}$ would furnish the corresponding aldehyde and recover back the active catalyst; however, the authors could not rule out an alternate pathway consisting of a hydride transfer from $\mathbf{X X V I I I ~ w i t h ~} \mathrm{Et}_{3} \mathrm{SiH}$ (path b).
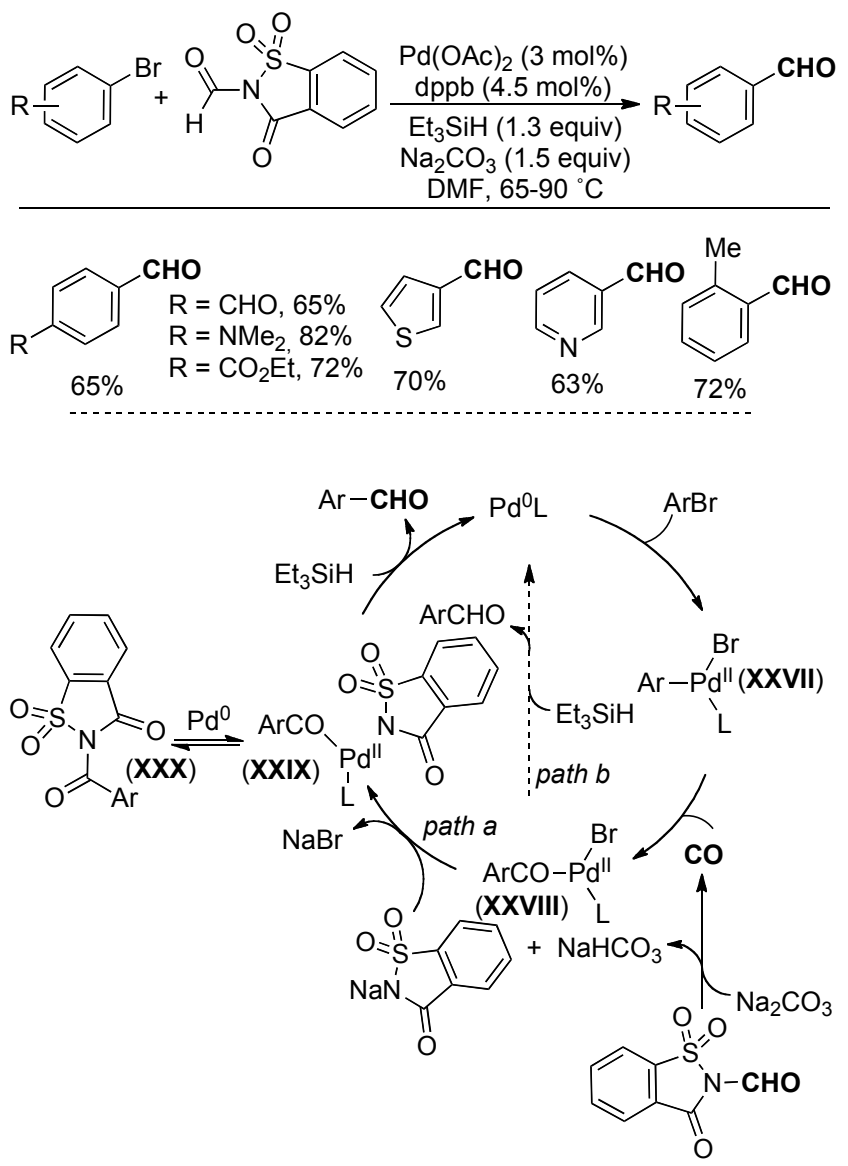

Scheme 21. Use of $\mathrm{N}$-formylsaccharin as CO source in Pd-catalyzed reductive carbonylation reactions.

In recent years, Skrydstrup and co-workers elegantly implemented 9-methylfluorene-9-carbonyl chloride (COgen) as an innovative CO source in a sealed two-chamber reactor (COware) for conducting a vast array of Pd-catalyzed carbonylation processes ${ }^{[48]}$ Interestingly, the use of simple and cheap potassium formate as reducing agent allowed for the reductive formylation of a wide variety of aryl iodides and bromides (Scheme 22). ${ }^{[49}$ ] High selectivity towards the formylation was achieved when using $\mathrm{Pd}(\mathrm{dba})_{2}$ along with monodentate phosphine ligands such as $\mathrm{PCy}_{3}$ (or its $\mathrm{HBF}_{4}$ salt) or CataXCium $\mathrm{A}$; intriguingly, the use of bulkier $\mathrm{P}(t \mathrm{Bu})_{3}$ led to the preferential formation of carboxylic acids. ${ }^{[50]}$ Remarkably, TBAI was required as phase-transfer agent for enhancing the catalyst performance. The protocol was characterized by its robustness and compatibility with the presence of numerous functional groups such as free-amines, aryl tosylates and nitrogen-containing heterocycles. The application for rapidly preparing isotopically labelled aldehydes in the presence of ${ }^{13} \mathrm{COgen}$ and/or $\mathrm{DCO}_{2} \mathrm{~K}$ is particularly noteworthy given the few methods available to produce such compounds. ${ }^{[49]}$ The synthetic utility of this method was illustrated by the rapid synthesis of ${ }^{13} \mathrm{C}$-labeled florbetaben, a powerful $\beta$-amyloid binding compound. ${ }^{[49]}$

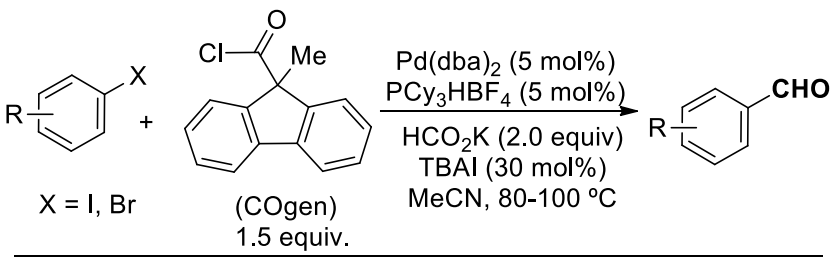<smiles>CC(C)(C)OCc1ccccc1NC(=O)OCc1ccc(NC(=O)C2CC2)nc1</smiles>

Scheme 22. Pd-catalyzed reductive carbonylation of aryl halides in a twochamber reactor.

Recently, the Liu group has implemented the advantageous use of carbon dioxide $\left(\mathrm{CO}_{2}\right)$ as environmentally friendly $\mathrm{C} 1$ source (vide infra) in palladium-catalyzed reductive formylation processes (Scheme 23). ${ }^{[51]}$ They found that the conversion of aryl iodides into the corresponding benzaldehydes could be accomplished with $\mathrm{CO}_{2}(1 \mathrm{MPa})$ in the presence of $\mathrm{Pd} / \mathrm{C}$ as catalyst, 1,8-diazabicylco[5.4.0]undec-7-ene (DBU) as base and poly(methylhydrosiloxane) (PMHS) as hydride source in MeCN at $80{ }^{\circ} \mathrm{C}$. This protocol was particularly efficient for the formylation of numerous aryl iodides; whereas substrates bearing electron-donating groups provided good to excellent yields, the presence of electron-withdrawing groups afforded the corresponding aldehydes in much lower yields. As expected, in these cases dehalogenated arenes were observed as a result of a rapid hydride transfer from the siloxane to the in situ formed oxidative addition species prior $\mathrm{CO}$ insertion. Remarkably, ortho substituents did not hamper the reaction and aryl bromides and chlorides did not undergo the formylation process. Interestingly, they gained some mechanistic insights by performing certain control experiments: (a) the formation of [DBU][HI] as an ionic liquid was detected, thus revealing a dual role of the base by activating the $\mathrm{CO}_{2}$ and neutralizing the $\mathrm{HI}$ released in the process; (b) benzoic acid did not produce benzaldehyde under the standard conditions ruling out an initial carboxylation process; (c) ${ }^{1} \mathrm{H}-\mathrm{NMR}$ analysis confirmed the formation of silylformate (XXXI) when mixing $\mathrm{PMHS}$ and $\mathrm{CO}_{2}$ in the presence of DBU. Accordingly, they proposed that silylformate species (XXXXI) react with the oxidative addition species (XXXII) to deliver the targeted aldehyde and silyloxypalladium complex (XXXIII). Finally, subsequent hydrogen transfer from PMHS and reduction of HPdl assisted by $\mathrm{DBU}$ regenerates the active $\mathrm{Pd}(0)$ catalyst. 

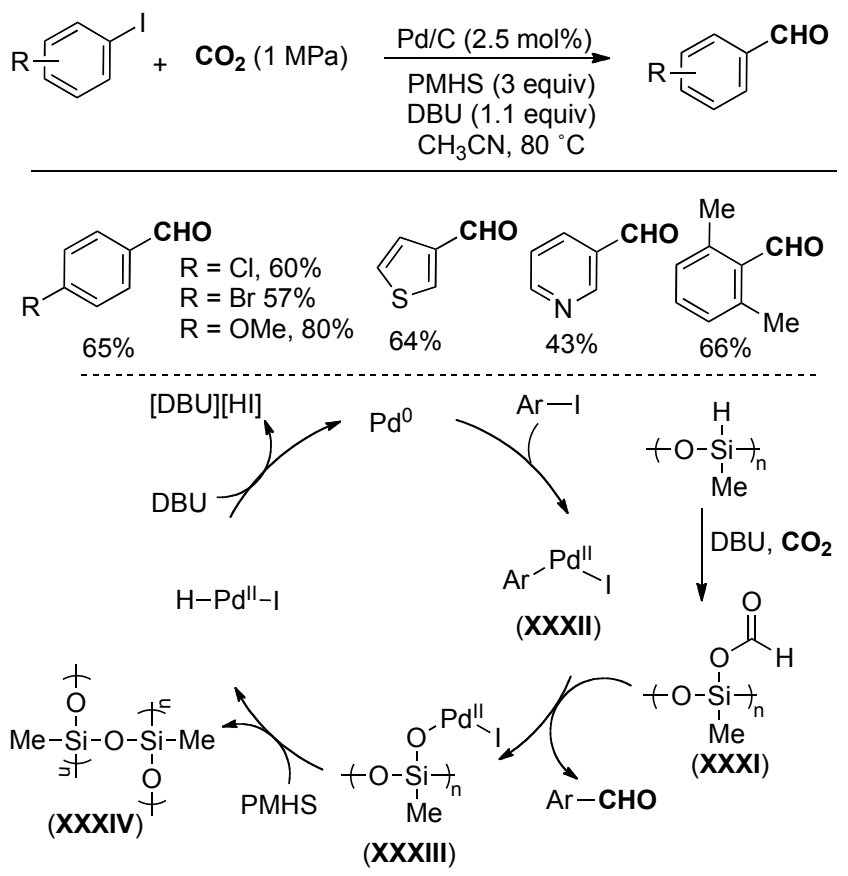

Scheme 23. Pd-catalyzed carbonylation of aryl iodides with $\mathrm{CO}_{2}$.

Despite the advances realized, most of the reductive carbonylation reactions reported to date are restricted to the use of aryl iodides, bromides or particularly activated aryl triflates. A major challenge in these endeavours for the years to come would imply the development of mild reductive carbonylations applicable to cheaper aryl chlorides and other environmentally friendly coupling partners such as $\mathrm{C}-\mathrm{O}$ electrophiles derived from phenols.

\section{Reductive Carboxylations with $\mathrm{CO}_{2}$}

Carbon dioxide $\left(\mathrm{CO}_{2}\right)$ is highly abundant, non-toxic, inexpensive and remarkably attractive as an excellent renewable $\mathrm{C} 1$ feedstock. ${ }^{[52]}$ The significant increase of global $\mathrm{CO}_{2}$ emissions in the atmosphere along with its negative impact on the environment have undoubtedly prompted chemists to face practical means for fixating $\mathrm{CO}_{2}$ into organic molecules. The successful implementation of such technologies could represent a direct alternative to the use of phosgene or $\mathrm{CO}$ as $\mathrm{C} 1$ source. Still, however, the high thermodynamic and kinetic stability of $\mathrm{CO}_{2}$ constitutes a serious drawback when devising $\mathrm{CO}_{2}$ fixation processes. Among all conceivable scenarios, the use of transition-metal catalysts represents one of the most powerful techniques to achieve $\mathrm{CO}_{2}$ insertion processes. Despite the latest elegant methodologies for fixating $\mathrm{CO}_{2}$ into useful organic compounds, ${ }^{[53]}$ the next section is mainly focused on the recently disclosed metal-catalyzed reductive carboxylations of organic halides and (pseudo)halides with $\mathrm{CO}_{2}$ in the field of homogeneous catalysis.

Owing to the prevalence of carboxylic acids in a wide range of medicinally relevant compounds and organic materials, a plethora of novel synthetic routes, particularly in a catalytic fashion, have recently been developed. In this regard, the direct carboxylation of organometallic species and other carbon nucleophiles with $\mathrm{CO}_{2}$ have emerged as powerful and advantageous alternatives to classical synthetic approaches for preparing carboxylic acids. ${ }^{[54,55]}$ Despite the advances realized, the need for stoichiometric amounts of well-defined and air- sensitive organometallic species limit the application profile of these rather appealing events. Therefore, the development of alternate user-friendly carboxylative processes operating in the absence of sensitive metal species and using readily available substrates is of utmost synthetic importance.
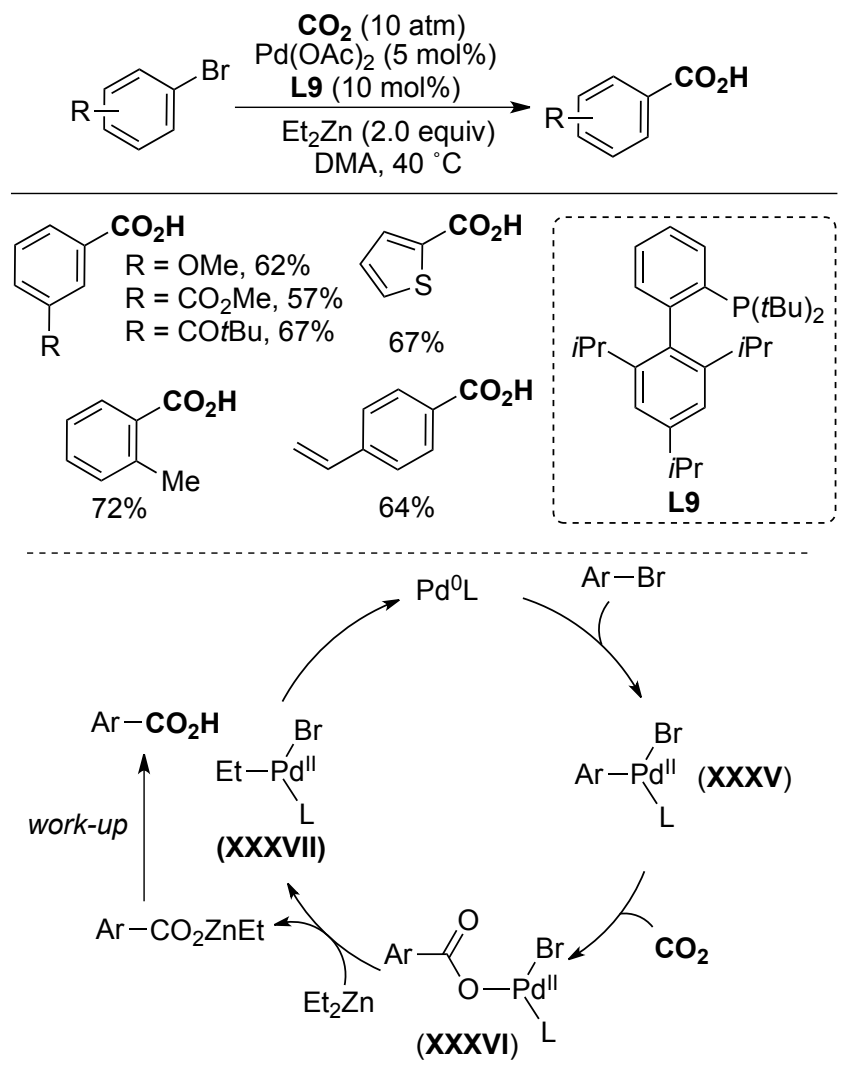

Scheme 24. Pd-catalyzed reductive carboxylation of aryl bromides.

Prompted by a seminal discovery of Osakada and Yamamoto using stoichiometric amounts of nickel salts, ${ }^{[56]}$ and by the excellent electrochemical methods reported by Périchon, Jutand, and Amatore, ${ }^{[57]}$ the Martin group reported in 2009 a $\mathrm{Pd}$-catalyzed reductive carboxylation of aryl bromides with $\mathrm{CO}_{2}$ utilizing $\mathrm{Et}_{2} \mathrm{Zn}$ as reducing agent (Scheme 24). ${ }^{\left[{ }^{[8]}\right.}$ As for many other cross-coupling methodologies, ${ }^{[1]}$ the nature of the ligand was critical for success, with $t B u X P h o s$ showing a unique reactivity. The use of structurally-related phosphines provided variable amounts of either dehalogenated or Negishi-type products, thus revealing the crucial importance of using a particular bulky and electron-rich phosphine to rapidly insert $\mathrm{CO}_{2}$ into the $\mathrm{Pd}-\mathrm{C}$ bond (XXXVI) while inhibiting the competitive transmetalation with $\mathrm{Et}_{2} \mathrm{Zn}$. Interestingly, reducing agents other than $\mathrm{Et}_{2} \mathrm{Zn}$ were found much less selective, leading to reduced arene or homocoupling products. While one might argue that the use of $\mathrm{Et}_{2} \mathrm{Zn}$ could compromise the chemoselectivity profile, this was not the case and numerous functional groups such as amines, (thio)ethers, ketones, alkenes, esters and even oxiranes were perfectly tolerated. Noteworthy, ortho substituents did not hamper the reductive carboxylation reaction. However, the method was restricted to the use of aryl bromides as substrates; indeed, it was found that aryl chlorides remained intact under the reaction conditions while the use of aryl iodides provided the corresponding carboxylic acid in comparatively lower yields. The mechanism was believed to involve an oxidative addition of an aryl bromide to an in situ generated $\mathrm{Pd}(0)$ catalyst, subsequent $\mathrm{CO}_{2}$ insertion 
and a final transmetallation with $\mathrm{Et}_{2} \mathrm{Zn}$ to deliver a zinc benzoate that upon hydrolytic work-up provides the corresponding benzoic acid (Scheme 24, bottom). The authors found that no benzoic acid was formed upon exposure of $\mathrm{PhZnBr}$ to the optimized reaction conditions; similarly, a simple $\mathrm{D}_{2} \mathrm{O}$ quench did not afford the corresponding deuterated arene. Accordingly, the intermediacy of arylzinc species as reaction intermediates was ruled out. Although this method established the state-of-the-art of reductive carboxylations of aryl halides in a catalytic fashion, the major drawbacks relied on the use of airsensitive and pyrophoric $\mathrm{Et}_{2} \mathrm{Zn}$ and the use of relatively high $\mathrm{CO}_{2}$ pressures (10 bar).

In 2012, the Tsuji group reported an elegant reductive carboxylation of more challenging and accessible aryl chlorides using nickel catalysis under mild reaction conditions (Scheme 25). ${ }^{[59]}$ It was found that the combination of $\mathrm{NiCl}_{2}\left(\mathrm{PPh}_{3}\right)_{2}, \mathrm{Mn}$ powder, $\mathrm{Et}_{4} \mathrm{NI}$ and $\mathrm{DMI}$ (1,3-dimethyl-2-imidazolidinone) at room temperature and atmospheric pressure of $\mathrm{CO}_{2}$ allowed the efficient conversion of aryl chlorides into the corresponding benzoic acids. Noteworthy, the addition of co-catalytic amounts of $\mathrm{PPh}_{3}$ proved beneficial for the process. The nature of the ligand was rather critical; thus, the inclusion of $\mathrm{PCy}_{3}$, dppe or bipyridine had a detrimental impact on reactivity. A similar behavior was observed when replacing $\mathrm{Mn}$ by $\mathrm{Zn}$ or $\mathrm{Mg}$ as reducing agents. Under these reaction conditions, a wide variety of aryl chlorides could smoothly be carboxylated, even in the presence of sensitive functional groups such as ester, amide or boronic esters, among others. Remarkably, this Nicatalyzed protocol was also suitable for the carboxylation of aryl bromides and activated aryl sulfonates such as tosylates and triflate derivatives. Notably, the use of $\mathrm{NiBr}_{2}$ (bpy) as catalyst also led to the successful carboxylation of various vinyl chlorides. Unfortunately, aryl chlorides bearing hydroxyl or amino groups and substrates possessing ortho-substituents could not be utilized. The proposed catalytic cycle consisted of an oxidative addition of an in situ generated $\mathrm{Ni}(0)$ catalyst,

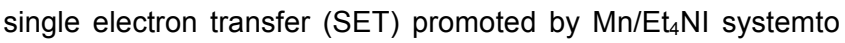
afford a $\mathrm{Ni}(\mathrm{I})$ intermediate (XXXIX), ${ }^{[2],[57]}$ thus setting up the stage for a $\mathrm{CO}_{2}$ insertion event (Scheme 25, bottom). The resulting nickel carboxylate was believed to furnish the corresponding manganese carboxylate by SET promoted by $\mathrm{Mn}$. Interestingly, stoichiometric experiments using $\mathrm{PhNiCl}\left(\mathrm{PPh}_{3}\right)_{2}$ and DFT calculations ${ }^{[60]}$ corroborated such scenario involving $\mathrm{Ni}(\mathrm{I})$ species in which the $\mathrm{CO}_{2}$ insertion was likely ratedetermining.
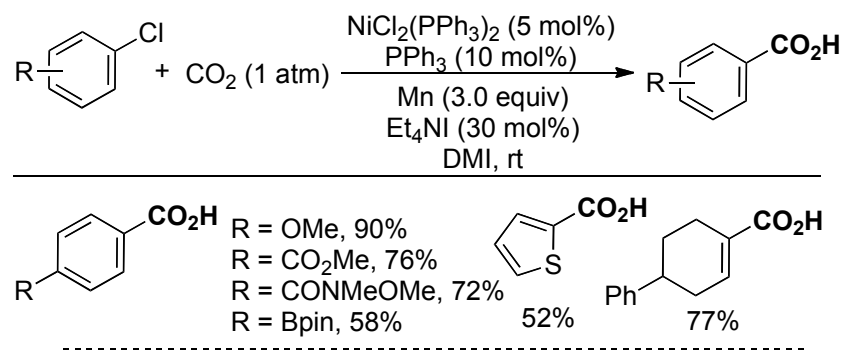

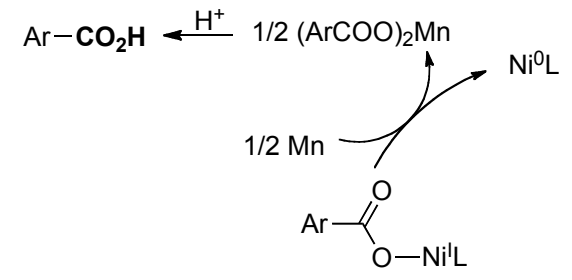

(IL)<smiles>CC(C)C(=O)O[Na]</smiles>

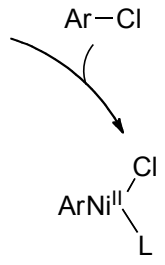

(XXXVIII)

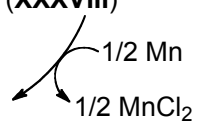

(XXXIX)

Scheme 25. Ni-catalyzed reductive carboxylation of aryl chlorides.

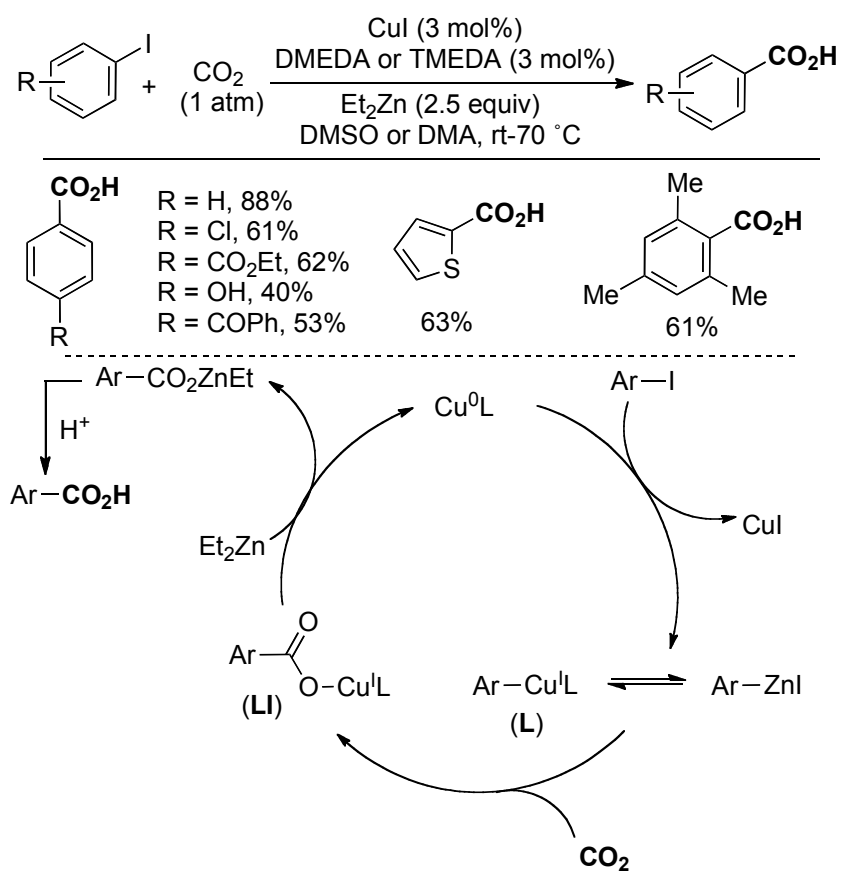

Scheme 26. Cu-catalyzed reductive carboxylation of aryl iodides.

Recently, the group of Daugulis introduced the use of costefficient copper catalysts to perform a related reductive carboxylation process with $\mathrm{CO}_{2}$ (Scheme 26). ${ }^{[61]}$ Although restricted to less accessible aryl iodide derivatives and to pyrophoric $\mathrm{Et}_{2} \mathrm{Zn}$ as reducing agent, the additional bonus for such a method relies on the use of low catalyst loadings of cheap and non-toxic Cul together with simple diamine ligands such as $N, N, N^{\prime}, N^{\prime}$-tetramethylethylenediamine (TMEDA) and $N, N$ '-dimethylethylenediamine (DMEDA). Interestingly, the Daugulis protocol was not as ligand-dependent as the Martin's ${ }^{[58]}$ and Tsuji's ${ }^{[59]}$ procedures; in this respect, a variety of diamines including 1,10-phenanthroline or 2,2'-bipyridine, among others, could be also used with similar results. Although relatively high reaction temperatures were required $\left(70^{\circ} \mathrm{C}\right)$, the method exhibited an excellent compatibility towards functional groups such as ester, aryl bromide, aryl chloride, amines, free 
alcohols and ketones. Moreover, sterically hindered aryl iodides smoothly underwent the reductive carboxylation, even at room temperature. The proposed reaction mechanism involved the reduction of $\mathrm{Cul}$ to $\mathrm{Cu}(0)$ species assisted by $\mathrm{Et}_{2} \mathrm{Zn}$, subsequent oxidative addition of the aryl iodide, $\mathrm{CO}_{2}$ insertion into the resulting $\mathrm{Ar}-\mathrm{Cu}(\mathrm{I})$ intermediate (L) and final transmetallation to deliver the corresponding zinc carboxylate with concomitant regeneration of the $\mathrm{Cu}(0)$ catalyst (Scheme 26, bottom). Control experiments performed with $\mathrm{Hg}$ as additive evidenced the possible involvement of copper clusters. Although a reversible aryl transfer step between copper and zinc species was postulated, the $\mathrm{CO}_{2}$ insertion event was believed to occur more rapidly into the $\mathrm{C}-\mathrm{Cu}$ bond than in the C-Zn bond.

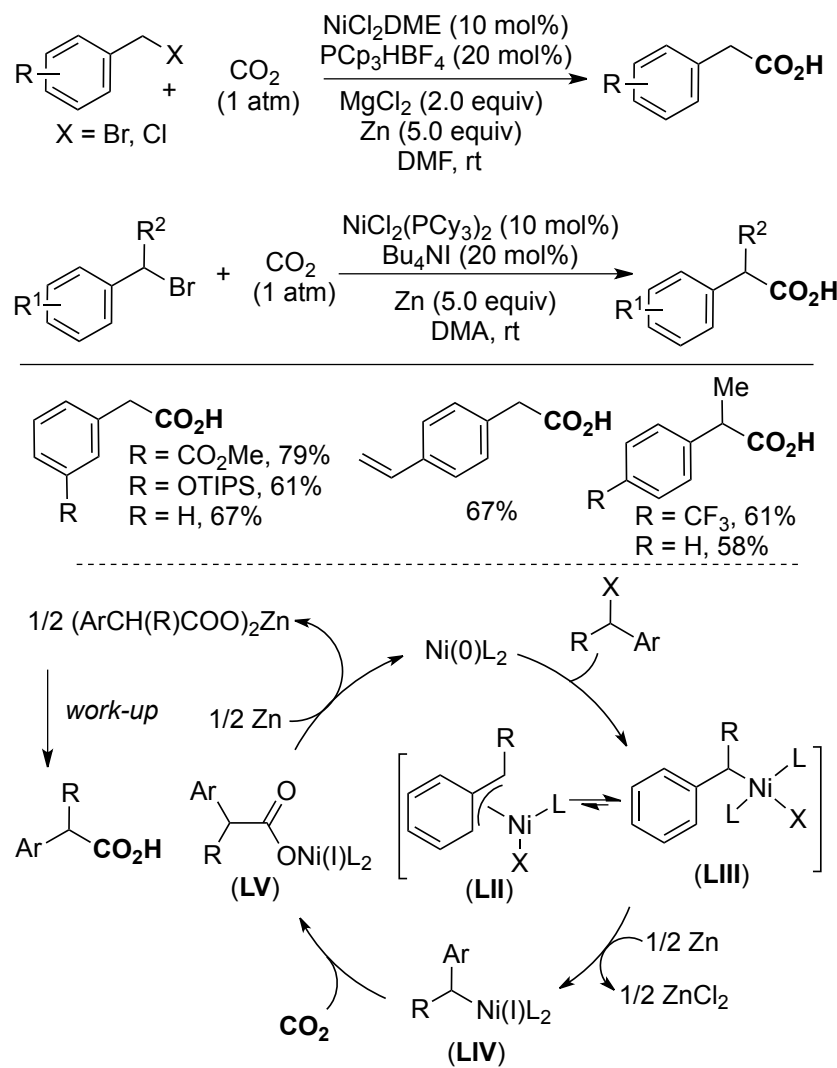

Scheme 27. Ni-catalyzed reductive carboxylation of benzyl halides.

The Martin group has recently extended the scope of the reductive carboxylation processes to the use of activated benzyl bromides and chlorides en route to synthetically valuable phenylacetic acids (Scheme 27). ${ }^{[62,63]}$ They found that primary benzyl halides were smoothly carboxylated at room temperature and atmospheric pressure of $\mathrm{CO}_{2}$ in the presence of a catalyst system based upon a cocktail of $\mathrm{NiCl}_{2}$. glyme, $\mathrm{PCp}_{3} \cdot \mathrm{HBF}_{4}$ and $\mathrm{MgCl}_{2}$ as additive. Alternatively, the carboxylation of secondary and tertiary benzyl halides could also be accomplished by using $\mathrm{NiCl}_{2}\left(\mathrm{PCy}_{3}\right)_{2}$ as catalyst and tetrabutylammonium iodide (TBAI) as additive. In all cases $\mathrm{Zn}$ dust was the reducing agent of choice. As for other related carboxylative protocols, the method accommodated a wide number of functional groups and substitution patterns; of particular significance is the tolerance of terminal olefins and aryl halides, moieties that are known to promote related carboxylative events with $\mathrm{Ni}$ catalysts, thus showing the remarkable chemoselectivity of the method towards the benzyl halide motif. Following up a similar rational to previous methods, the authors suggested a mechanism involving an initial oxidative addition of benzyl halide to in situ generated $\mathrm{Ni}(0)$ species, delivering a nickel(II) intermediate that likely coexists in a rapid equilibrium of $\eta^{3}$ - and $\eta^{1}$-bound nickel species (LII and LIII; Scheme 27, bottom). $\mathrm{Zn}$ is then believed to assist the generation of a more nucleophilic $\mathrm{Ni}(\mathrm{I})$ species that rapidly undergo $\mathrm{CO}_{2}$ insertion, an observation that is in analogy with related electrochemical methods. ${ }^{[24],[57]}$ An alternative hypothesis consisting of a comproportionation event of LII or LIII with a $\mathrm{Ni}(0)$ center could not be entirely excluded. ${ }^{[64]}$ Subsequently, a final transmetallation with $\mathrm{Zn}$ delivers the targeted carboxylic acid while regenerating the active propagating $\mathrm{Ni}(0)$ species. Noteworthy, the authors managed to isolate and characterize by X-ray crystallography complex LII. The study of its reactivity, together with the ability of radical traps to inhibit the reaction pointed towards the generation of $\mathrm{Ni}(\mathrm{I})$ species via SET processes.

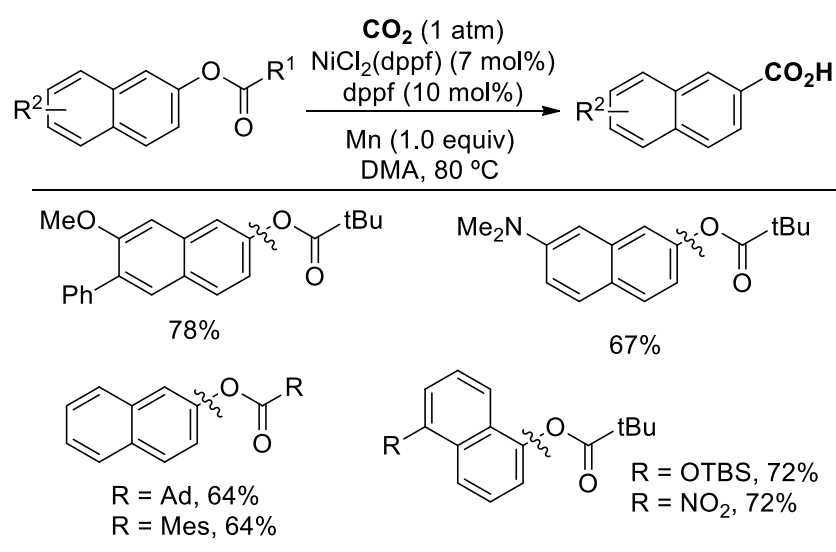

Scheme 28. Ni-catalyzed reductive carboxylation of $\mathrm{C}\left(\mathrm{sp}^{2}\right)-\mathrm{O}$ electrophiles.

In recent years unactivated $\mathrm{C}-\mathrm{O}$ electrophiles have emerged as advantageous and environmentally friendly (pseudo)halide coupling partners in a wide range of crosscoupling processes. ${ }^{[65]}$ Martin and co-workers recently implemented their use in $\mathrm{Ni}$-catalyzed reductive carboxylations with $\mathrm{CO}_{2}$, thus avoiding the typical halide waste associated to the use of aryl halides (Scheme 28). ${ }^{[66]}$ The particular combination of $\mathrm{NiCl}_{2}$ (dppf) and $\mathrm{Mn}$ dust in DMA as solvent allowed the carboxylation of several $\mathrm{C}\left(\mathrm{sp}^{2}\right)-\mathrm{O}$ bonds to occur at $80^{\circ} \mathrm{C}$ and atmospheric pressure of $\mathrm{CO}_{2}$. The use of co-catalytic amounts of $1,1^{\prime}$-bis(phenylphosphino)ferrocene (dppf) proved essential to enhance the catalyst efficiency. As expected, the nature of the ligand exerted a profound influence on the reaction outcome and other related ferrocene-type ligands entirely inhibited the reductive carboxylation reaction.

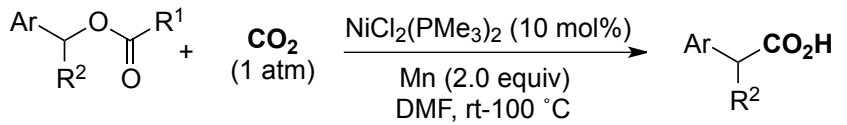

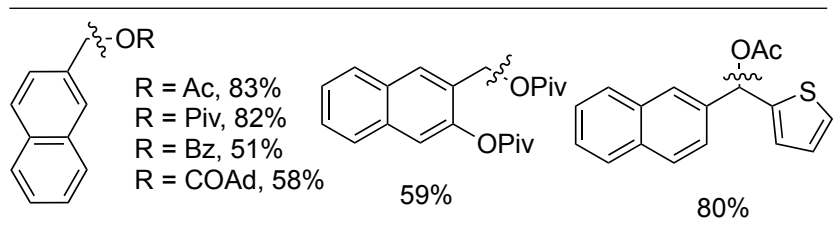<smiles>CCOC(=O)c1cccc(C(=O)c2ccc3ccccc3c2)c1</smiles> 
Scheme 29. Ni-catalyzed reductive carboxylation of $\mathrm{C}\left(\mathrm{sp}^{3}\right)-\mathrm{O}$ electrophiles.

Notably, the reductive carboxylation of more challenging $\mathrm{C}\left(\mathrm{sp}^{3}\right)-\mathrm{O}$ motifs was also within reach when using $\mathrm{NiCl}_{2}\left(\mathrm{PMe}_{3}\right)_{2}$ as catalyst and $\mathrm{Mn}$ as reducing agent in DMF at room temperature (Scheme 29). ${ }^{[66]}$ This catalyst system was found applicable for the carboxylation of a wide variety of benzyl-type substrates. In this respect, not only bulky benzyl pivalates but also simpler acetates and benzoates smoothly underwent the reductive process. Remarkably, both primary and secondary benzyl-type derivatives were perfectly accommodated and, unlike previous carboxylative protocols based on the use of organic halides, the authors found that this new protocol was amenable for the coupling of substrates bearing various heterocycles. Despite the synthetic value of the method, the scope was primarily restricted to the use of $\pi$-extended systems, an observation that is in line with recent developments in the $\mathrm{C}-\mathrm{O}$ bond-cleavage arena. ${ }^{[67]}$ It was postulated that a partial dearomatization of the arene ring might occur prior oxidative addition; therefore, an extended $\pi$-system might bind to the $\mathrm{Ni}$ center in a $\eta^{2}$-fashion via the Dewar-Chatt-Duncanson model, thus retaining, unlike a regular arene, certain aromaticity that provides extra stabilization. ${ }^{[68]}$ The authors overcome such limitation by introducing traceless hemilabile directing groups when using $\mathrm{C}\left(\mathrm{sp}^{3}\right)-\mathrm{O}$ electrophiles (Scheme 29). ${ }^{[69]}$ The authors postulated that the presence of such directing group might accelerate the rate of oxidative addition with regular arenes while opening up coordination sites on the $\mathrm{Ni}$ center, thus facilitating the binding of $\mathrm{CO}_{2}$ and its subsequent insertion event. The use of 2-methoxy acetate derivatives was particularly effective, allowing for the successful reductive carboxylation of differently substituted benzyl ester derivatives lacking $\pi$-extended systems. In analogy with previous studies, they proposed a reaction pathway involving $\mathrm{Ni}(\mathrm{l})$ species as the key intermediates.

While the field of metal-catalyzed reductive carboxylation of organic halides or (pseudo)halides has reached a considerable level of development, this field of expertise is still at its infancy when compared with other $\mathrm{CO}_{2}$ fixation methods. This is likely due to the fact that the underlying mechanism from which these reactions operate is fundamentally speculative at this point. Therefore, we anticipate than in depth mechanistic studies might lead to the foundation of new reductive carboxylative events counterintuitive at first sight. We certainly expect a bright future in the years to come in this particular area of expertise.

\section{Summary and Outlook}

This mini-review seeks to provide an up-to-date overview of the latest advances in the field of metal-catalyzed reductive couplings of carbonyl-type compounds with organic halides and/or (pseudo)halide derivatives. The wealth of literature data reported in recent years suggests that these methods might represent a direct and straightforward alternative to the common use of well-defined, stoichiometric, and in many cases, air-sensitive organometallic species. The key aspect of metalcatalyzed reductive coupling reactions relies on the in situ generation of catalytically competent organometallic species that rapidly react with a variety of electrophilic counterparts containing carbonyl-type compounds. Despite the advances realized, some of these protocols are still limited to the use of aryl halides or activated (pseudo)halides such as aryl sulfonates; therefore, the implementation of more appealing coupling partners such as cheap aryl chlorides and environmentally friendlier $\mathrm{C}-\mathrm{O}$ electrophiles would open up new synthetic opportunities of paramount chemical significance. At present, little knowledge has been gathered regarding the mechanism of these transformations and only indirect evidences have been performed in order to propose a rational mechanistic scenario. The study of reaction mechanisms via the isolation of the putative reaction intermediates has demonstrated its critical role for the discovery of new reactions within the cross-coupling arena. Therefore, we anticipate that efforts along these lines would have a significant impact on the field of metal-catalyzed reductive coupling reactions. Additionally, the implementation of robust and widely-tolerant asymmetric processes within this field of expertise would allow for the design of new synthetic routes to advanced intermediates via the use of unconventional bonddisconnections and from simple precursors.

\section{Acknowledgements}

We thank ICIQ Foundation, the European Research Council (ERC-277883) and MICINN (CTQ2012-34054) for financial support. A.C thanks MICINN for a JdC fellowship.

[1] For selected reviews: a) D. S. Surry, S. L. Buchwald, Chem. Sci. 2011, 2, 27-50; b) R. Jana, T. P. Pathak, M. S. Sigman, Chem. Rev. 2011, 111, 1417-1492; c) G. C . Fu, Acc. Chem. Res. 2008, 41, 1555-1564; d) R. Martin, S. L. Buchwald, Acc. Chem. Res. 2008, 41, 1461-1473; e) D. Alberico, M. E. Scott, M. Lautens, Chem. Rev. 2007, 107, 174238; f) Metal-Catalyzed Cross-Coupling Reactions (Eds: F. Diederich, A. Meijere) Wiley-VCH, Weinheim, 2004.

[2] For selected reviews: a) B. -J. Li, Z. -J. Shi, Chem. Soc. Rev. 2012, 41, 5588-5598; b) C. Liu, H. Zhang, W. Shi, A. Lei, Chem. Rev. 2011, 111, 1780-1824; c) W. Shi, C. Liu, A. Lei, Chem. Soc. Rev. 2011, 40, 2761-2776; d) C. -L. Sun, B. -J. Li, Z. -J. Shi, Chem. Commun. 2010, $46,677-685$.

[3] Bew, S. P. In Comprehensive Organic Functional Groups Transformation II; Katritzky, A. R., Taylor, R. J. K., Eds.; Elsevier: Oxford, 2005 ; pp 19.

[4] For related reductive coupling processes not using organic halides as coupling partners: a) "Organonickel Chemistry" in Organometallics in Synthesis: Fourth Manual, (Eds: B.H. Lipshutz) Wiley, Hoboken, N.J., 2013; b) M. Jeganmohan, C. H. Cheng, Chem. Eur. J. 2008, 14, 10876-10886; c) J. Montgomery, G. J. Sormunen, Top. Curr. Chem. 2007, 279, 1-23; d) R. M. Moslin, K. Miller-Moslin, T. F. Jamison, Chem. Commun. 2007, 4441-4449; e) E. Skucas, M. -Y. Ngai, V. Komanduri, M. J. Krische, Acc. Chem. Res. 2007, 40, 1394-1401; f) J. Montgomery, Angew. Chem. 2004, 116, 3980-3998; Angew. Chem. Int Ed. 2004, 49, 3890-3908; g) S. Ikeda, Angew. Chem. 2003, 115, 52765278; Angew. Chem. Int. Ed. 2003, 42, 5120-5122.

[5] For selected references on the use of organic halides in reductive coupling events see: a) L. -Y. Liao, X. -R. Kong, X. -F. Duan, J. Org. Chem. 2014, 79, 777-782; b) Q. Qian, Z. Zang, S. Wang, Y. Chen, K. Lin, H. Gong, Synlett 2013, 619-624; c) Y. Peng, L. Luo, C. -S. Yan, J. -J. Zhang, Y. -W. Wang, J. Org. Chem. 2013, 78, 10960-10967; d) D. A. Everson, B. A. Jones, D. J. Weix, J. Am. Chem. Soc. 2012, 134, 6146-6159; c) S.Wang, Q. Qian, H. Gong, Org. Lett. 2012, 12, 33523355; e) Y. Chang-Song Yan, Y. Peng, X. -B. Xu, Y. -W. Wang, Chem. Eur. J. 2012, 18, 6039-6048; f) L. L. Anka-Lufford, M. R. Prinsell, D. J. Weix, J. Org. Chem, 2012, 77, 9989-1000; g) D. A. Everson, R. Shrestha, D. J. Weix, J. Am. Chem. Soc. 2010, 132, 920921.

[6] a) P. Wender, B. L. Miller, Nature 2009, 460, 197-201; b) B. M. Trost, Acc. Chem. Res. 2002, 35, 695-705; c) B. M. Trost, Angew. Chem. Int. Ed. Engl. 1995, 34, 259-281.

[7] For selected reviews see: a) J. -Y. Nedelec, J. Perichon, M. Troupel, Top. Curr. Chem. 1997, 185, 141-173; b) J. Chaussard, J. C. Folest, J. 
-Y. Nedelec, J. Perichon, S. Sibille, M. Troupel, Synthesis 1990, 5, 369-381.

[8] P. Knochel, W. Dohle, N. Gommermann, F. F. Kneisel, F. Kopp, T Korn, I. Sapountzis, V. Anh Vu, Angew. Chem. 2003, 115, 4438-4456; Angew. Chem. Int. Ed. 2003, 48, 4302-4320.

[9] For selected examples: a) H. Tanaka, S. Yamashita, T. Hamatani, Y. Ikemoto, S. Torii, Chem. Lett. 1986, 1611-1614; b) C. Peter, J. Einhorn, J. L. Luche, Tetrahedron Lett. 1985, 26, 1449-1452; c) C. Perier, J. L. Luche, J. Org. Chem. 1985, 50, 910-912; d) T. Hiyama, M. Sawahata, Y. Kusano, Chem Lett. 1985, 611-612; e) M. Wada, K. Akiba, Tetrahedron Lett. 1985, 26, 4211-4212; f) T. Imamoto, T. Kusumoto, Y. Tawarayama, Y. Sugiura, T. Mita, J. Org. Chem. 1984, 49, 3904-3912; g) G. P. Boldrini, D. Savoia, E. Tagliavini, C. Trombin, A. UmaniRonchi, J. Org. Chem, 1983, 48, 4108-4111; h) J. Nokami, J. Otera, T. Sudo, R. Okawara, Organometallics, 1983, 2, 191-193; i) T. Hiyama, M. Obayashi, A. Nakamura, Organometallics, 1982, 1, 1249-1251; j) J. L. Luche, J. C. Damiano, J. Am. Chem. Soc. 1980, 102, 7927-7300; k) C. Blomberg, F. A: Hartog, Synthesis 1977, 18-30.

[10] a) J. J. Miller, M. S. Sigman, J. Am. Chem. Soc. 2007, 129, 27522753; b) A. Fürstner, Chem. Rev. 1999, 99, 991-1045; c) A. Fürstner, N. Shi, J. Am. Chem. Soc. 1996, 118, 2533-2534.

[11] R. W. Armstrong, J. M. Beau, S. H. Cheon, W. J. Christ, H. Fujioka, W. H. Ham, L. D. Hawkins, H. Jin, S. H. Kang J. Am. Chem. Soc. 1989, $111,7530-7533$.

[12] G. C. Hargarden, P. J. Guiry, Adv. Synth. Catal. 2007, 349, 2407-2424

[13] K. K. Majumdar, C. -H. Cheng, Org. Lett. 2000, 2, 2295-2298.

[14] For related reductive couplings of aldehydes with allylic carbonates see: Z. Tan, X. Wan, Z. Zang, Q. Qian, W. Deng, H. Gong, Chem. Commun. 2014, 3827-3830.

[15] Y. -C. Huang, K. K. Majumdar, C. -H. Cheng, J. Org. Chem. 2002, 67, 1682-1684.

[16] M. Durandetti, C. Gosmini, J. Perichon, Tetrahedron 2007, 63, 11461153.

[17] J. -X. Hu, C. -Y. Li, W. -J. Sheng, Y. -X. Jia, J. -R. Gao, Chem. Eur. J. 2011, 17, 5234-5237.

[18] H. Fillon, C. Gosmini, J. Perichon, Tetrahedron 2003, 59, 8199-8202.

[19] For selected examples on the electrochemical coupling reactions of carbonyl-type compounds, see: a) M. Durandetti, C. Meignen, J. Perichon, Org. Lett. 2003, 5, 317-320; b) S. Seka, O. Buriez, J. Perichon, Chem. Eur. J. 2003, 9, 3597-3603; c) S. Seka, O. Buriez, J. -Y. Nedelec, J. Perichon, Chem. Eur. J. 2002, 8, 2534-2538; d) M. Durandetti, J. -Y. Nedelec, J. Perichon, Org. Lett. 2001, 3, 2073-2076; e) C. Amatore, A. Jutand, J. Perichon, Y. Rollin, Monatsh. Chem. 2000 131, 1293-1304; f) M. Durandetti, J. Perichon, J. -Y. Nedelec Tetrahedron Lett. 1999, 40, 9009-9013; g) A. Conan, S. Sibille, J. Perichon, J. Org. Chem. 1991, 56, 2018-2024.

[20] G. Cahiez, A. Moyeux, Chem. Rev. 2010, 110, 1435-1462.

[21] F. Wu, W. Lu, Q. Qian, Q. Ren, H. Gong, Org. Lett. 2012, 14, 30443047.

[22] W. Lu, Z. Liang, Y. Zhang, F. Wu, Q. Qian, H. Gong, Synthesis 2013, 2234-2240.

[23] a) S. W. Smith, G. C. Fu J. Am. Chem. Soc. 2008, 130, 12645-12647; b) C. Fisher, G. C. Fu, J. Am. Chem Soc. 2005, 127, 4594-4595; c) J. Zhou, G. C. Fu, J. Am. Chem. Soc. 2003, 125, 14726-14727.

[24] For related catalytic electrochemical methods based on the generation of metal species in odd oxidation states, see: ref. 19

[25] A. C. Wotal, D. J. Weix, Org. Lett. 2012, 14, 1476-1479.

[26] T. Yamamoto, T. Kohara, A. Yamamoto, Bull. Chem. Soc. Jpn. 1981 54, 2010-2016; b) T. Yamamoto, T. Kohara, K. Osakada, A. Yamamoto, Bull. Chem. Soc. Jpn, 1983, 56, 2147-2153.

[27] A. H. Cherney, N. T. Kadunce, S. E. Reisman, J. Am. Chem. Soc. 2013, 135, 7442-7445.

[28] I. Kazmierski, M. Bastienne, C. Gosmini, J. -M Paris, J. Périchon, J. Org. Chem. 2004, 69, 936-942.
[29] H. Yin, C. Zhao, H. You, K. Lin, H. Gong, Chem. Commun. 2012, 7034-7036.

[30] J. -C. Hsieh, C. -H. Cheng, Chem. Commun. 2005, 4554-4556.

[31] a) A. A. Pletnev, R. C. Larock, Tetrahedron Lett. 2002, 43, 2133-2136; b) A. A. Pletnev, R. C. Larock, J. Org. Chem. 2002, 67, 4554-4556.

[32] J. -C. Hsieh, Y. -C. Chen, A. -Y. Cheng, H. -C. Tseng, Org. Lett. 2012, 14, 1282-1285.

[33] Y. Xia, F. Hu, Z. Liu, P. Qu, R. Ge, C. Ma, Y. Zhang, J. Wang, Org. Lett. 2013, 15, 1784-1787.

[34] R. Shrestha, S. C. M. Dorn, D. J. Weix, J. Am. Chem. Soc. 2013, 135, 751-762.

[35] R. Shrestha, D. J. Weix, Org. Lett. 2011, 13, 2766-2769.

[36] a) X. -F. Wu, H. Neumann, M. Beller, Chem. Rev. 2013, 113, 1-35; b) X. -F. Wu, H. Neumann, M. Beller, Chem. Soc. Rev. 2011, 40, 49865009; c) Q. Liu, H. Zhang, A. Lei, Angew. Chem. 2011, 119, 1097810989; Angew. Chem. Int. Ed. 2011, 50, 10788-10799; d) A. Brennführer, H. Neumann, M. Beller, Angew. Chem. 2009, 121, 41764196; Angew. Chem. Int. Ed. 2009, 48, 4114-4133;

[37] A. Schoenberg, R. F. Heck, J. Am. Chem. Soc. 1974, 96, 7761-7764.

[38] a) A. B. Smith III, L. Kürti, A. H. Davulcu, Y. S. Cho, Org. Process. Res. Dev. 2007, 11, 19-24; b) V. P. Baillargeon, J. K. Stille, J. Am. Chem. Soc. 1986, 108, 452-461; c) V. P. Baillargeon, J. K. Stille, J. Am. Chem. Soc. 1983, 105, 7175-7176.

[39] a) L. Ashfield, C. F. J. Barnard, Org. Process Res. Dev. 2007, 11, 3943; b) D. C. Behenna, J. L. Stockdill, B. M. Stoltz, Angew. Chem. 2007, 119, 4155-4158; Angew. Chem. Int. Ed. 2007, 46, 4077-4080; c) H. Kotsuki, P. K. Datta, H. Suenaga, Synthesis 1996, 470-472.

[40] a) M. -Z. Cai, H. Zhao, J. Zhou, C. -S. Song, Synth. Commun. 2002, 32, 923-926; b) Y. Ben-David, M. Portnoy, D. Milstein, J. Chem. Soc. Chem. Commun. 1989, 1816-1817; c) I. Pri-Bar, O. Buchman, J. Org. Chem. 1984, 49, 4009-4011.

[41] a) A. Brennführer, H. Neumann, M. Beller, Synlett 2007, 2537-2540; b) A. Brennführer, H. Neumann, S. Klaus, T. Riermeier, J. Almena, M. Beller, Tetrahedron 2007, 63, 6252-6258; c) S. Klaus, H. Neumann, A. Zapf, D. Strübing, S. Hübner, J. Almena, T. Riermeier, P. Groß, M. Sarich, W. -R. Krahnert, K. Rossen, M. Beller, Angew. Chem. 2006, 118, 161-165; Angew. Chem. Int. Ed. 2006, 45, 154-158.

[42] A. G. Sergeev, A. Spannenberg, M. Beller, J. Am. Chem. Soc. 2008, 130, 15549-15563

[43] H. Neumann, R. Kadyrov, X. -F. Wu, M. Beller, Chem. Asian J. 2012, 7, 2213-2216.

[44] A. S. Singh, B. M. Bhanage, J. M. Nagarkar, Tetrahedron Lett. 2011, 52, 2383-2386

[45] S. Cacchi, G. Fabrizi, A. Goggiamani, J. Comb. Chem. 2004, 6, 692694

[46] T. Ueda, H. Konishi, K. Manabe, Angew. Chem. 2013, 125, 87738777; Angew. Chem. Int. Ed. 2013, 52, 8611-8615.

[47] T. Cocheta, V. Bellostaa, A. Greinerb, D. Rocheb, J. Cossy, Synlett 2011, 1920-1922.

[48] S. Korsager, D. U. Nielsen, R. H. Taaning, T. Skrydstrup, Angew. Chem. 2013, 125, 9945-9948; Angew. Chem. Int. Ed. 2013, 52, 97639766 and references cited therein.

[49] S. Korsager, R. H. Taaning, A. T. Lindhardt, T. Skrydstrup, J. Org. Chem. 2013, 78, 6112-6120.

[50] See for example: a) S. Korsager, R. H. Taaning, T. Skrydstrup, J. Am. Chem. Soc. 2013, 135, 2891-2894; b) M. N. Burhardt, R. H. Taaning, T. Skrydstrup, Org. Lett. 2013, 15, 948-951 and references cited therein; c) P. Hermange, A. T. Lindhardt, R. H. Taaning, K. Bjerglund, D. Lupp, T. Skrydstrup, J. Am. Chem. Soc. 2011, 133, 6061-6071.

[51] B. Yu, Y. Zhao, H. Zhang, J. Xu, L. Hao, X. Gao, Z. Liu, Chem. Commun. 2014, 50, 2330-2333.

[52] For recent reviews dealing with the use of $\mathrm{CO}_{2}$ : a) Y. Tsuji, T. Fujihara, Chem. Commun. 2012, 9956-9964; b) M. Cokoja, C. Bruckmeier, B. 
Rieger, W. A. Herrmann, F. E. Kühn, Angew. Chem. 2011, 123, 86628690; Angew. Chem. Int. Ed. 2011, 50, 8510-8537; c) R. Martin, A. W. Kleij, ChemSusChem 2011, 4, 1259-1263; d) K. Huang, C. -L. Sun, Z. -L. Shi, Chem. Soc. Rev. 2011, 40, 2435-2452; e) Carbon Dioxide as Chemical Feedstock (Eds: M. Aresta), Wiley-VCH, Weinheim, 2010; f) T. Sakakura, J. -C. Choi, H. Yasuda, Chem. Rev. 2007, 107, 23652387 and references cited therein.

[53] Recent selected examples: a) O. Jacquet, X. Frogneux, C. D. N. Gomes, T. Cantat, Chem. Sci. 2013, 4, 2127-2131; b) S. Kikuchi, K. Sekine, T. Ishida, T. Yamada, Angew. Chem. 2012, 124, 7095-7098; Angew. Chem. Int. Ed. 2012, 51, 6989-6992; c) L. Zhang, J. Cheng, B. Carry, Z. Hou, J. Am. Chem. Soc. 2012, 134, 14314-14317; d) S. Li, W. Yuan, Y. Ma, Angew. Chem. 2011, 123, 2626-2630; Angew. Chem. Int Ed. 2011, 50, 2578-2582; e) T. Fujihara, T. Xu, K. Semba, J. Terao, Y. Tsuji, Angew. Chem. 2011, 123, 543-547; Angew. Chem. Int. Ed. 2011, 50, 523-527; f) H. Mizuno, J. Takaya, N. Iwasawa, J. Am. Chem. Soc. 2011, 133, 1251-1253; g) I. I. F. Boogaerts, S. P. Nolan, J. Am. Chem. Soc. 2010, 132, 8858-8859; h) L. Zhang, J. Cheng, T. Ohishi, Z. Hou, Angew. Chem. 2010, 122, 8852-8855; Angew. Chem. Int. Ed. 2010, 49, 8670-8673.

[54] For selected references: a) K. Kobayashi, Y. Kondo, Org. Lett. 2009, 11, 2035-2037; b) J. Takaya, S. Tadami, K. Ukai, N. Iwasawa, Org. Lett. 2008, 10, 2697-2700; c) T. Ohishi, M. Nishiura, Z. Hou, Angew. Chem. 2008, 120, 5876-5879; Angew. Chem. Int. Ed. 2008, 47, 57925795; d) H. Ochiai, M. Jang, K. Hirano, H. Yorimitsu, K. Oshima, Org. Lett. 2008, 10, 2681-2683; e) C. S. Yeung, V. M. Dong, J. Am. Chem. Soc. 2008, 130, 7826-7827; f) K. Ukai, M. Aoki, J. Takaya, N. Iwasawa, J. Am. Chem. Soc. 2006, 128, 8706-8707.

[55] A. Correa, R. Martin, Angew. Chem. 2009, 121, 6317-6320; Angew. Chem. Int. Ed. 2009, 48, 6201-6204.

[56] K. Osakada; R. Sato, R.; T. Yamamoto, T. Organometallics 1994, 13, 4645-4647.

[57] For selected examples on the metal-catalyzed electrochemical reductive carboxylation of organic halides: a) S. Torii, H. Tanaka, T. Hamatani, K. Morisaki, A. Jutand, F. Pflüger, J. F. Fauvarque, Chem. Lett. 1986, 169-172; b) J. F. Fauvarque, A. Jutand, M. François, M. A. Petit, J. Appl. Electrochem. 1988, 18, 116-119; c) C. Amatore, A. Jutand, J. Am. Chem. Soc. 1991, 113, 2819-2825; d) C. Amatore, A. Jutand, F. Khalil, M. F. Nielsen, J. Am. Chem. Soc. 1992, 114, 70767085.

[58] A. Correa, R. Martin, J. Am. Chem. Soc. 2009, 131, 15974-15975.

[59] T. Fujihara, K. Nogi, T. Xu, J. Terao, Y. Tsuji, J. Am. Chem. Soc. 2012, 134, 9106-9109.

[60] F. B. Sayyed, Y. Tsuji, S. Sakaki, Chem. Commun. 2013, 1071510717.

[61] H. Tran-Vu, O. Daugulis, ACS Catal. 2013, 3, 2417-2420.

[62] T. León, A. Correa, R. Martin, J. Am. Chem. Soc. 2013, 135, 12211224.

[63] For related synthesis of phenylacetic acids not using organic halides via a hydrocarboxylation event with $\mathrm{CO}_{2}$, see: a) M. D. Greenhalgh, S. P. Thomas, J. Am. Chem. Soc. 2012, 134, 11900-11903; b) C. M. Williams, J. B. Johnson, T. Rovis, J. Am. Chem. Soc. 2008, 130, 14936-14937; c) H. Hoberg, S. Gross, A. Milchereit, Angew. Chem. 1987, 99, 567-569; Angew. Chem. Int. Ed. 1987, 26, 571-572; d) H. Hoberg, Y. Peres, A. J. Milchereit, J. Organomet. Chem. 1986, 307, C38-C40.

[64] For selected comproportionation events in route to $\mathrm{Ni}(\mathrm{I})$ species, see: (a) J. Cornella, E. Gómez-Bengoa, R. Martin J. Am. Chem. Soc. 2013, 135, 1997-2009; (b) A. Velian, S. Lin, A. J. M. Miller, M. W. Day, T. Agapie, J. Am. Chem. Soc. 2010, 132, 6296-6297; (c) G. D. Jones, J. L. Martin, C. McFarland, O. R. Allen, R. E. Hall, A. D. Haley, R. J. Brandon, T. Konovalova, P. J. Desrochers, P. Pulay, D. A. J. Vicic, J. Am. Chem. Soc. 2006, 128, 13175-13183.

[65] For recent reviews: a) M. Tehetena, N. K. Garg, Org. Process Res. Dev. 2013, 17, 29-39; b) J. Yamaguchi, K. Muto, K. Itami, Eur. J. Org. Chem. 2013, 19-30; c) A. Correa, J. Cornella, R. Martin, Angew. Chem. 2013, 125, 1928-1930; Angew. Chem. Int. Ed. 2013, 52, 1878-1880; d) B. M. Rosen, K. W. Quasdorf, D. A. Wilkson, N. Zhang, A. -M. Resmerita, N. K. Garg, B. Percec, Chem. Rev. 2011, 111, 1346-1416; e) B. -J. Li, D. -G. Yu, C. -L. Sun, Z. -J. Shi, Chem. Eur. J. 2011, 17, 1728-1759; f) D. -G. Yu, B. -J. Li, Z. -J. Shi, Acc. Chem. Res. 2010, 43, 1486-1495

[66] A. Correa, T. León, R. Martin, J. Am. Chem. Soc. 2014, 136, $1062-$ 1069.

[67] The use of extended $\pi$-systems has been a requisite for seminal discoveries in the area of inert $\mathrm{C}-\mathrm{O}$ bond-cleavage reactions, with most of compounds in the substrate scope being extended $\pi$-systems. See for example: a) H. M. Wisniewska, E. C. Swift, E. R. J. Jarvo, J. Am. Chem. Soc. 2013, 135, 9083-9095; b) B. L. H. Taylor, E. C. Swift, J. D. Waetzig, E. R. J. Jarvo, J. Am. Chem. Soc. 2011, 133, 389-391; c) B. L. Taylor, M. R. Harris, E. R. J. Jarvo, Angew. Chem. 2012, 124, 7910-7913; Angew. Chem. Int. Ed. 2012, 51, 7790-7793; d) D. -G. Yu, Z. -J. Shi, Angew. Chem. 2011, 123, 7235-7238; Angew. Chem. Int. Ed. 2011, 50, 7097-7100; e) D. -G. Yu, B. -J. Li, S. -F. Zheng, B. -T. Guan, B. -Q. Wang, Z. -J. Shi, Angew. Chem. 2010, 122, 4670-4674; Angew. Chem. Int. Ed. 2010, 49, 4566-4570.

[68] a) J. Chatt, L. A. Duncanson, L. M. Venanzi, J. Chem. Soc. 1955, 4456-4460; b) J. Chatt, L. A. Duncanson, J. Chem. Soc. 1953, 29392947 ; c) M. J. S. Dewar, Bull. Soc. Chim. Fr. 1951, 18, C71-79.

[69] G. Rousseau, B. Breit, Angew. Chem. 2011, 123, 2498-22543; Angew. Chem. Int. Ed. 2011, 50, 2450-2494.
Received: ((will be filled in by the editorial staff)) Revised: ((will be filled in by the editorial staff)) Published online: ((will be filled in by the editorial staff)) 
Layout 2:

\section{FULL PAPER}

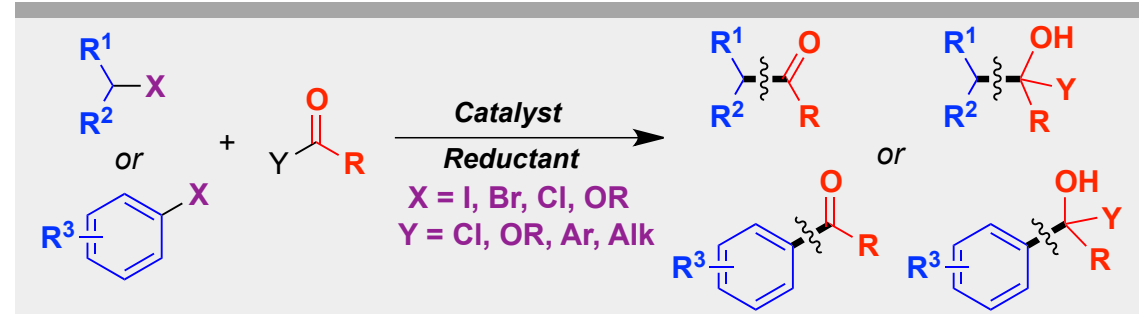

Metal-catalyzed reductive couplings of a variety of electrophilic aryl halides and (pseudo)halides with carbonyl-type compounds have undergone impressive development along the last years. In this review, the recent findings in this field are summarized, with particular emphasis on the mechanistic interpretation of the results and the future aspects of this area of expertise.
Catalytic Reductive Coupling Reactions

Toni Moragas, Arkaitz Correa* and Ruben Martin*

$\square \square-\square \square$

Metal-catalyzed Reductive Coupling

Reactions of Organic Halides with

Carbonyl-type Compounds 